\title{
Low Frequency Filtering and Real Business Cycles
}

\author{
Robert G. King and Sergio T. Rebelo \\ Rochester Center for Economic Research \\ Working Paper No. 205
}




\title{
LOW FREQUENCY FILTERING AND REAL BUSINESS CYCLES
}

\author{
Robert G. King \\ University of Rochester \\ and \\ Rochester Center for Economic Research \\ AND \\ Sergio T. Rebelo \\ Northwestern University \\ Portuguese Catholic University \\ and \\ Rochester Center for Economic Research \\ Working Paper No. 205
}

February 1988

Revised: October 1989

The authors acknowledge financial support from the National Science Foundation. This research has benefited from discussions with Marianne Baxter, Gary Hansen, Robert Hodrick, Charles Plosser, Edward Prescott and Mark Watson. However, the authors are residual claimants with respect to errors of any sort. 



\section{Lor Frequency Filtering and Real Business Cycles}

\section{Abstract}

It is conmon practice in business cycle analysis for researchers to filter out lov frequency components, so as to focus their efforts on business cycles rather than economic grovth. In recent real business cycle research, this "trend elimination" has most frequently been undertaken with the HP filter due to Robert Hodrick and Edvard Prescott [1980].

In this paper, ne provide a detailed discussion of the HP filter from time and frequency domain perspectives, motivating it as a generalization of the vell known exponential smoothing filter. Further, $\nabla e$ shog that the HP filter-in parameterizations applicable in large samples-contains a centered fourth difference, so that it is capable of rendering stationary time series that are "difference stationary" and, indeed, integrated of higher order.

Hovever, our application of the HP filter to U.S. time series and to the simulated outcomes of real business cycle models leads us to question its videspread use as a unique method of trend elimination, prior to computation of moments summarizing model and actual time series. We provide examples of hov standard HP practice produces major departures from alternative, more traditional viers of cyclical fluctuations. Notably, HP filtering dramatically alters measures of persistence, variability and comovement. Thus, ve reconmend some alterations in existing practice of communicating research results on business cycle models. 



\section{Introduction}

A hallmark of modern equilibrium business cycle theory is the vien that grovth, business cycles and seasonal variations are to be studied within a unified framevork. Even though rational economic agents are presumed to respond differently to shocks of varying duration, dynamic economic theory generally imposes concrete and extensive restrictions across frequencies. For one example, the manner in phich agents respond to varying seasonal opportunities provides information about hov they will respond to temporary opportunities during the course of business cycles. For another, the manner in vhich labor supply responds to the permanent vage and vealth changes occurring during economic growth restricts responses at business cycle frequencies.

Yet, beginning vith Kydland and Prescott [1982], many studies in the real business cycle research area apply the HP filter-due to Hodrick and Prescott [1980]-to both time series generated from an artificial economy and actual data before making conclusions about the properties of the model and its congruence vith observations. This practice corresponds to an implicit definition of "the business cycle frequencies" and a decision to domnplay the implications of the model at other frequencies, generally on the grounds that these represent grovth rather than business cycles.

Reading the literature on real business cycles, one can easily come to the conclusion that the practice of "lov frequency filtering" has relatively minor consequences for hor one thinks about economic models and their consistency ith observed time series. This paper demonstrates that the opposite conclusion is true: the practice of lod frequency filtering has major consequences for both the "stylized" facts of business cycles and the perceived operation of dynamic economic models. In fact, the components of 
time series removed by mechanical application of the HP filter are sufficiently important that one may feel that the baby is being thrown out vith the bath vater in terms of business cycle research. Consequently, we provide some specific recommendations for alterations in practice, i.e., in the reporting of research results on business cycles.

Our motivation for this investigation derived from tro sources, which we provide to the reader as a puzzle to be investigated in the remainder of the paper.

\section{Implications for Simulated Time Series}

Dur first exposure to the potential importance of HP filtering involved an attempt to replicate some results obtained in Gary Hansen's [1985] analysis of the effects of varying the labor supply elasticity in a basic real business cycle model.1

Table I-1 provides a fer population moments, basically those reported by Hansen [1985], vith and vithout HP filtering. ${ }^{2}$ The model economy is one in phich the single source of uncertainty is a trend stationary technology shock to total factor productivity; it is detailed in Ring, Plosser and Rebelo [1988a] and reviered in section III belor. From this table, it is clear that HP filtering alters the moment implications of the model in a quantitatively important manner, but that this influence is not constant across series.

\footnotetext{
the thank Gary Hansen for providing some simulation results for unfiltered versions of his model [1985] that confirmed our conjectures that filtering, not model solution methods or model parameter values, lay at the heart of major differences in moments.

2Reporting of these selected moments is common in discussions of implications of real business cycle models, as-for example-in KcCallum's [1989] survey, Tables 1 and 2 .
} 
First, HP filtering, which extracts a component from the original series, lowers volatility as measured by the standard deviation columns in table 1 . Second, HP filtering alters the relative volatilities of different series (the standard deviation of a variable divided by that of output). In particular, it increases the relative volatility of investment and hours vhile lovering that of consumption, the real vage and the capital stock. Third, the correlations betreen individual series and output-a measure of cyclical sensitivity-are substantially altered by HP filtering. Notably, the cyclical variation in capital and labor input is dramatically altered by filtering. In the unfiltered economy, capital's correlation with output is .73 and that of labor with output is .79. With filtering, capital's correlation drops to .07 and that of labor rises to .98 .

\section{HP Filtering of Some U.S. Post Var Time Series}

Our second indication of the potential importance of HP filtering came from Marianne Baxter's empirical rork (Baxter [1988] and Baxter and Stockman [1988]) on stylized facts of economic fluctuations in the United States and other countries. ${ }^{3}$ To provide some empirical background to our subsequent analysis, ve begin by displaying an application of the HP filter to a measure of aggregate economic activity and a measure of labor input. These are the logarithm of U.S. real gross national product, which ve denote $y_{t}$, and the logarithm of per capita average hours vorked, vhich ve denote $N_{t}$.

${ }^{3}$ We thank Karianne Baxter for suggesting the revealing examples contained in this section and for technical assistance in producing these results. 
Like other lov frequency filters, the HP filter can be vieved as extracting growth and cyclical components from the data. 4 To start, let us focus on the $y_{t}$ series and begin by dividing $y_{t}$ into a linear trend $(\gamma t)$ and a residual deviation from a linear trend (so that the residual $y_{t}^{\mathbf{r}}=y_{t}-\gamma t$ ). If the grovth component is assumed to be a deterministic trend, then the business cycle component is $\mathrm{y}_{t}^{r}$. Under the HP filtering procedure, by contrast, the time series is permitted to have a stochastic gronth component. In addition to extracting a linear trend-if one exists in the series under study-HP filtering also removes some additional variation phose properties depend on the series in pays detailed in section II belor. The HP cyclical component is then defined as the difference betreen the original time series and the HP grovth component.

Implications for Real GNP: Figure I-1 plots the HP gronth component versus the linear trend component of real gross national product. A relatively common reaction to this figure is that these ways of removing grovth are not too different. But it turns out that there are major consequences for business cycle components.

In order to study the practical implications of alternative detrending methods, ve construct the HP stochastic growth component by subtracting a linear trend from the HP growth component (taking the vertical difference between the series in Figure 1). He call this component $\operatorname{HP}^{g}\left(y_{t}\right)$.

4In part, our discussion in this section and belor involves the issue of hor best to define business cycles. One possibility- - hich is sometimes discussed in evaluation of mechanical procedures such as the HP filter-would be to select some mechanical method that broadly replicated the stylized facts reported by WBER researchers following Mitchell [1927,1951] and Burns and Mitchell [1941]. Hovever, preliminary vork by King and Plosser [1989] leads us to believe that the IBER methods should be subject to some scrutiny as vell. 
Summarizing our definitions, the alternative decompositions are

$$
y_{t}=\gamma t+y_{t}^{r}=\gamma t+H^{c}\left(y_{t}\right)+H P^{B}\left(y_{t}\right) \text {, }
$$

i.e., the HP cyclical and stochastic gropth components sum to the residual from the deterministic trend.

Figure I-2 makes clear that the HP stochastic gropth component constitutes a major portion of the departure of output from a linear trend, so that the implied cyclical components arising from these tro methods of trend elimination are very different both in terms of magnitude and persistence. Hotably, the autocorrelation correlation coefficient of $y_{t}^{r}$ at the annual lag is .72. Figure I-3 plots the $\mathrm{HP}$ cyclical component $\left(\mathrm{HP}^{\mathrm{C}}\left(\mathrm{y}_{t}\right)\right.$ ) of real GNP, thich is a rapidly fluctuating series, as may be judged from its autocorrelation structure, thich is presented in Table I-2, panel A. The autocorrelation at a year lag (four quarters), for example, is only .09, phich is an order of magnitude smaller than the autocorrelation coefficient for $\operatorname{HP}^{\mathrm{r}}\left(\mathrm{y}_{\mathrm{t}}\right)$ at the same lag.

Implications for GNP and Labor Input: Figure I-4 plots $\mathbf{y}_{\mathrm{t}}^{\mathrm{r}}$ versus the departures of our labor input measure from its mean (i.e., $N_{t}-\bar{N}$ ). There is not a strong relationship: the contemporaneous correlation is only .06 . Hovever, then one compares the HP cyclical components of output and hours in Figure I-5, there is a striking coincidence: the contemporaneous correlation is .86. Further information on the implications of filtering for correlations among variables is contained in Table I-2.

\section{Outline of Our Analysis}

To this point, re have shown that lov frequency filtering-using the Hodrick and Prescott [1980] filter-has important implications on moments of 
U.S. time series and a simulated real business cycle model. In developing an explanation of the origin of these results and their practical consequences for business cycle research ve proceed as follovs. In section II, ve first discuss vhat linear filtering is and then revied some facts about linear filters. We next derive the HP grovth and cyclical filters as a direct generalization of the vell-knom exponential smoothing filter of Brovn [1962]. In section III, ve apply the HP filter to some basic real business cycle models to further develop the sorts of implications suggested by section III. Building on these results, in section IV, ve provide a concrete set of recomendations about hov to best report results of investigations into business cycles. Section $V$ is a brief summary and conclusion.

\section{Lov Frequency Filtering}

There is a lengthy history in macroeconomics of filtering time series. For example, there is extensive use of moving averages of time series by Mitchell [1930] and Kuznets [1930] in their analyses of business cycles and economic grovth. Further, applications of moving averages and other linear filters can sometimes lead to important statistical artifacts in time series. For example, Fishman [1969] summarizes research that points out hov the apparent long seings in economic activity suggested by Kuznets [1961] might potentially have arisen simply from his application of moving averages rather than as a property of underlying economic time series.

In this section, our objectives are trofold. First, in section II.1, ve provide an overvien of analytical tools for studying the implications of linear filters. This section should be skipped by readers vho are comfortable vith introductory treatments of frequency domain methods (e.g., 
Harvey [1981, Chapter 3]). Second, in section II.1, ve motivate the HP filter as a generalization of the familiar class of exponential smoothing (ES) procedures studied by Brown [1962]. Throughout our discussion in this section, ve vill focus our attention on a representative time series $y_{t}$, which ve treat as the logarithm of an original series so that its first difference is a gropth rate.

In filtering $y_{t}$, a researcher is motivated by one of several objectives: (i) extraction of a component such as a grosth, cyclical or seasonal component; (ii) transformation to induce stationarity; or (iii) mitigation of measurement error that is assumed to be particularly important at specific frequencies. He concentrate on the first tro motivations, since a detailed treatment of measurement error vould require grappling vith details of a specific application.

To focus our discussion, then, consider the idea that a particular economic model makes predictions about a "business cycle" component of a time series and that the researcher viens the series as containing both grovth and business cycle components,

$$
y_{t}=y_{t}^{g}+y_{t}^{c}
$$

where $y_{t}^{g}$ is the gronth component and $y_{t}^{c}$ is the business cycle component. Representing $y_{t}^{g}$ as a moving average (possibly tro sided) of observed $y_{t}$ permits extraction of the grouth component $\left(y_{t}^{g}\right)$ and the cyclical component $\left(y_{t}^{c}\right)$. That is, suppose that ve assume that

$$
y_{t}^{g}=\sum_{j=-\infty}^{D} g_{j} y_{t-j}=G(B) y_{t}
$$

vhere $B$ is the backshift operator vith $B^{n} x_{t}=x_{t-n}$ for $n_{<}^{>} 0$. Then, since 
$y_{t}^{c}=y_{t}-y_{t}^{g}$, it follons that $y_{t}^{c}$ is also a moving average of $y_{t}$,

$$
y_{t}^{c}=[1-G(B)] y_{t} \equiv C(B) y_{t}
$$

In the language of filtering theory, $G(B)$ and $C(B)=[1-G(B)]$ are linear filters and ve nor explore some of their properties.

\section{II.1 Some Facts About Linear Filters}

In order to discuss why a specific linear filter may be described as a 10 , frequency filter, we are led to consideration of the Fourier transform of a linear filter (also called the frequency response function of the filter). For example, the frequency response of the grovth filter is

$$
\tilde{G}(\omega)=\sum_{j=-\infty}^{\infty} g_{j} \exp (-i j \omega)
$$

vhere $i$ denotes the imaginary number $\sqrt{(-1)}$ and vhere $\omega$ is frequency measured in radians, i.e., $-\pi \leq \omega \leq \pi$.

Gain and Phase Decomposition: At a given frequency $\omega$, the frequency response $\tilde{G}(\omega)$ is simply a complex number, so that it may be oritten in polar form as $\tilde{G}(\omega)=\Gamma(\omega) \exp (-i \Psi(\omega))$, where $\Gamma(\omega)=|\tilde{G}(\omega)|$ and $\Psi(\omega)$ are real numbers for fixed $\omega$. In these expressions and belor, $|x|$ denotes the modulus of $x$ (the square root of the product of $x$ and its conjugate). The gain of the linear filter, $\Gamma(\omega)$, yields a measure-at the specified frequency $\omega$ - of the increase in the arplitude of the filtered series over the original series. The phase, $\Psi(\omega)$, yields a measure of the time displacement attributable to the linear filter, again at the specified frequency $\omega$. The frequency response function can be decomposed into the gain function $\Gamma(\omega)$ and phase function $\Psi(\omega)$ by replicating the preceding decomposition at each value of $\omega$. 
To take a concrete example, suppose that a time series is strictly periodic vith a period of $2 \pi / \omega^{*}$. Then application of the linear filter $G$ rould simply alter the range of this periodic function by $\Gamma\left(\omega^{*}\right)=\left|G\left(\omega^{*}\right)\right|$, as illustrated in Figure II-1a. Further, Figure II-1b illustrates the hypothetical phase shift effect of a linear filter.

Symmetric Filters: In our analysis, ve vill focus on filters that possess a symetry property in that $g_{j}=g_{-j}$. For any such filter, it is possible to shor that

$$
\tilde{G}(\omega)=g_{0}+2 \sum_{j=1}^{\infty} g_{j} \cos (j \omega)
$$

using the trigonometric identity $2 \cos (x)=\{\exp (i x)+\exp (-i x)\}$. Symmetric filters have the important property that they do not induce a phase shift, i.e., $\Psi(\omega)=0$ for all $\omega$, since the Fourier transform $\tilde{G}(\omega)$ is real for a symetric filter. Thus, the gain function is equal to the frequency response, so that we use these terms interchangeably belor.

Further, in the class of symetric filters, it is easy to see that

$$
\tilde{G}(0)=\sum_{j=-\infty}^{\infty} g_{j}=1
$$

is a necessary and sufficient condition for a filter to have the property that it has unit gain at zero frequency. 5 Thus, by extension, the associated cyclical filter $C(B)=[1-G(B)]$ vill place zero veight on zero frequency Dhenever $\tilde{G}(0)=1$.

5This property obtains for symetric filters since $\cos (0)=1$ and it follows directly that $\vec{G}(0)=1$. Moreover, this property holds as well for nonsymetric filters since $\exp (0)=1$ implies that $\tilde{G}(0)=1$ under the condition that the filter veights sum to unity. 
By restricting attention to symetric filters, then, ve can simply express their implications by plotting the gain for various values of $w$. Figure II-2a depicts the gain function of an idealized grodth filter that emphasizes only frequencies up to some maximum $\omega^{*}$. It has unit gain for frequencies $0 \leq \omega \leq \omega^{*}$ and zero gain for $\omega^{*} \leq \omega \leq \pi$. Figure II-2b shors the gain of its cyclical counterpart, $C(B)=[1-G(B)]$. Hovever, as discussed by Koopmans [1974, pages 176-185], it is not possible to actually apply such an ideal filter to a finite length data set, since its construction requires an infinite number of veights. Adaptation of the ideal filter to a finite veight context-including procedures such as truncation of the filter veights-generates problems that make the resulting filter imperfect. For example, Koopmans [1974, figure 6.7, page 185], demonstrates that the squared gain of the filter obtained via truncation is not flat over either $0 \leq \omega \leq \omega^{*}$ or $\omega^{*} \leq \omega \leq \pi$. Rather, there is "leakage" from those frequencies for which the ideal filter's gain is zero to those for phich it is unity. For this reason, ,e consider the linear filters arising from some commonly analyzed minimization problems, which take explicitly into account the length of the data set.

\section{II.2 Analysis of Some Common Linear Filters}

In many practical contexts, one frequently approaches the task of extracting unobserved components by solving a minimization problem. Tro noted examples are the problem (ES) which leads to the exponential smoothing filters for grovth and cyclical components and the problem (HP) phich leads to the Hodrick-Prescott [1980] filters for gropth and cyclical components. 6

60ur formulation of the HP problem is slightly different from that originally presented in Hodrick and Prescott [1980], in terms of treatment of endpoints. 
(ES)

$$
\min _{\left\{y_{t}^{g}\right\}_{t=1}^{T}} \sum_{t=1}^{T}\left[\left(y_{t}-y_{t}^{g}\right)^{2}+\lambda\left(y_{t}^{g}-y_{t-1}^{g}\right)^{2}\right]
$$

(HP)

$$
\underset{\left\{y_{t}^{g}\right\}_{t=0}^{T+1}}{\min } \sum_{t=1}^{T}\left[\left(y_{t}-y_{t}^{g}\right)^{2}+\lambda\left[\left(y_{t+1}^{g}-y_{t}^{g}\right)-\left(y_{t}^{g}-y_{t-1}^{g}\right)\right]^{2}\right] .
$$

In practice, the ES program vould contain an additional parameter-a constant mean of the grovth rate-to permit the minimal extraction of a deterministic linear trend for each chosen value of $\lambda$. The BP program automatically involves minimal extraction of a linear trend component, since this specification involves no change in the grorth rate. Thus, throughout our discussion, ve proceed as though a linear trend had already been removed from data.

Each of these minimization problems contains a parameter $\lambda$ that "penalizes" changes in the grovth component (in problem (ES)) or in the acceleration of the gropth component (in problem (HP)). Belov, ve vill use the first order conditions from these problems to characterize the associated linear filters. For the minimization problem (ES), the first order condition takes the form

$$
0=-2\left[y_{t}-y_{t}^{g}\right]+2 \lambda\left[y_{t}^{g}-y_{t-1}^{g}\right]-2 \lambda\left[y_{t+1}^{g}-y_{t}^{g}\right]
$$

For the minimization problem (HP), the first order condition takes the form

Hovever, this difference is unimportant given our focus on the "infinite sample" version of the filter. 


$$
\begin{aligned}
0=-2\left(y_{t}-y_{t}^{g}\right) & +2 \lambda\left[\left(y_{t}^{g}-y_{t-1}^{g}\right)-\left(y_{t-1}^{g}-y_{t-2}^{g}\right)\right] \\
& -4 \lambda\left[\left(y_{t+1}^{g}-y_{t}^{g}\right)-\left(y_{t}^{g}-y_{t-1}^{g}\right)\right] \\
& +2 \lambda\left[\left(y_{t+2}^{g}-y_{t+1}^{g}\right)-\left(y_{t+1}^{g}-y_{t}^{g}\right)\right]
\end{aligned}
$$

In each case, then, the first order condition links $y_{t}^{c}=y_{t}-y_{t}^{b}$ to changes in the growth component in adjacent periods. Belor, this shared characteristic vill play an important role in analysis of the grovth and cyclical filters associated vith these minimization problems.

In studying the optimal linear filters that solve these first-order conditions, ve vill consider the limiting version that obtains as the historical record length $(T)$ is driven to infinity. This results in relatively simple formulae describing the filters and provides the maximum opportunity for these to match the perfect log frequency filter described earlier. In this case, each of the first order conditions can be vritten in the form $F(B) y_{t}^{g}=y_{t}$. The $F(B)$ polynomials associated vith the tro problems are:

$$
\begin{aligned}
& F_{E S}(B)=-\lambda B^{-1}+(1+2 \lambda)-\lambda B=\left[\lambda(1-B)\left(1-B^{-1}\right)+1\right] \\
& F_{H P}(B)=\left[\lambda B^{-2}-4 \lambda B^{-1}+(6 \lambda+1)-4 \lambda B+\lambda B^{2}\right]=\left[\lambda(1-B)^{2}\left(1-B^{-1}\right)^{2}+1\right] .
\end{aligned}
$$

In order to find the grovth and cyclical filter, re need to invert $F(B)$ since $G(B)=[F(B)]^{-1}$ and $C(B)=1-G(B)=[F(B)-1][F(B)]^{-1}$. The details of this process are relatively easy for the ES filter; Appendix $A$ records the more tedious calculations for the HP filter. 
Gropth and Cyclical Components Via Exponential Smoothing

The extraction of lor frequency components via exponential smoothing has a long tradition in economics, having been employed-to cite only one example-in Friedman's [1967] research on the permanent income hypothesis. In contrast to that application, hovever, the problem (ES) leads to a tro sided exponential smoothing filter since we do not constrain $y_{t}^{g}$ to be a function solely of past history. Manipulating the relevant first order condition for the ES filter, ve find that

$$
C(B)=[F(B)-1][F(B)]^{-1}=\frac{\lambda[1-B]\left[1-B^{-1}\right]}{1+\lambda[1-B]\left[1-B^{-1}\right]} \text {. }
$$

Thus, ve find that the ES cyclical filter contains forvard and backward differences. A key implication of this finding is that the ES filter vould render stationary Nelson and Plosser's [1982] differenced stationary stochastic processes and also integrated processes of order tro, phose grotth rates are not stationary.

Our convenient expression for the cyclical filter's Fourier transform is

$$
\begin{aligned}
\tilde{c}(\omega) & =[F(\exp (-i \omega))-1] / F(\exp (-i \omega)) \\
& =\frac{\lambda[1-\exp (-i \omega)][1-\exp (i \omega)]}{1+\lambda[1-\exp (-i \omega)][1-\exp (i \omega)]}=\frac{2 \lambda[1-\cos (\omega)]}{1+2 \lambda[1-\cos (\omega)]},
\end{aligned}
$$

where the third equality makes use of the trigonometric identity discussed earlier. Thus, the cyclical filter has zero veight at the zero frequency (since $\cos (0)=1$ ) and assigns a reight close to unity at high frequencies (since $\cos (\pi)=-1, \vec{c}(\pi)=4 \lambda /(1+4 \lambda)$, which is close to one for large $\lambda$ ). Figure II-3 plots the gain of this cyclical filter for some alternative values of the smoothing parameter $\lambda$. Higher values of $\lambda$ shift the gain function uprard, raising the gain closer to unity for each fixed frequency. 
Analysis of the cyclical filter in the time domain is slightly messier. To undertake this analysis, re define $\theta$ to be the smallest root of $F$, i.e., $F(\theta)=F\left(\theta^{-1}\right)=0$. This parameter is related to $\lambda$ by the equation $\theta=\left\{(1+2 \lambda)-\left[(1+2 \lambda)^{2}-4 \lambda^{2}\right]^{1 / 2}\right\} /(2 \lambda)$, so that it is real and less than 1 for any $\lambda>0$. The grovth filter can then be expressed as $G(B)=F(B)^{-1}=$ $(\theta / \lambda)[1-\theta B]^{-1}\left[1-\theta B^{-1}\right]^{-1}$. From a straightforvard expansion,

$$
y_{t}^{g}=\left[\frac{(\theta / \lambda)}{1-\theta^{2}}\right]\left[\sum_{s=0}^{\infty} \theta^{s} y_{t-s}+\sum_{s=0}^{\infty} \theta^{s} y_{t+s}\right]
$$

i.e., the gropth component is a tro sided exponentially reighted moving average of the original series. Similarly, the cyclical filter can be expressed as :

$$
C(B)=\frac{\theta[1-B]\left[1-B^{-1}\right]}{\lambda[1-\theta B]\left[1-\theta B^{-1}\right]},
$$

which also makes clear that the effects of second differencing $[1-\mathrm{B}]\left[1-\mathrm{B}^{-1}\right]$ in the numerator are partly undone by the presence of $[1-\theta \mathrm{B}]\left[1-\theta \mathrm{B}^{-1}\right]$ in the denominator. In fact, if $\theta$ vere unity ( $\nabla$ hich is true in the limit as $\lambda \rightarrow_{\infty}$ ), then numerator and denominator terms vould cancel. In practical applications $\theta$ is closer to .9 , so that vhile this filter vill render stationary an integrated time series, it will generally preserve more lon frequency content than the first difference filter.

Filter veights for the cyclical filter C(B) are shown in Figure II-4 for a sample value of the smoothing parameter $(\lambda=60)$. Larger values of $\lambda-\nabla h i c h$ penalize changes in the grorth component-lead to smoother gropth components. Thus, they lead to values of $\theta$ closer to unity (in the limit as $\lambda \rightarrow \infty, \theta \rightarrow 1$ 
so that $\left.C(B)=1, i . e ., y_{t}^{c}=y_{t}\right)$. The values of $\theta$ for some alternative values of $\lambda$ are given in Table II-1.

Gronth and Cyclical Filters via the Hodrick-Prescott Method

It turns out that the HP filters are closely related to those derived above. Manipulating the relevant first order condition, the HP cyclical filter $C(B)$ may be vritten as

$$
C(B)=[F(B)-1]\left[F(B)^{-1}\right]=\frac{\lambda[1-B]^{2}\left[1-B^{-1}\right]^{2}}{1+\lambda[1-B]^{2}\left[1-B^{-1}\right]^{2}}
$$

Hence, the HP cyclical filter is also capable of rendering stationary any integrated process up to fourth order, since there are four differences in the numerator.

As with the exponential smoothing filter explored earlier, it turns out that the Fourier transform of the cyclical component filter has a particularly simple form:

$$
\tilde{c}(\omega)=\frac{4 \lambda[1-\cos (\omega)]^{2}}{1+4 \lambda[1-\cos (\omega)]^{2}} .
$$

Thus, the cyclical component filter places zero veight on the zero frequency $[\tilde{C}(0)=0]$ and close to unit veight on high frequencies $[\tilde{C}(\pi)=16 \lambda /(1+16 \lambda)]$. These features are reflected in Figure II-5, phich plots the gain for various values of $\lambda$. Increasing $\lambda$ shifts the gain function upvard, moving a given frequency's gain closer to unity.

Developing time domain representations of the filter is once again more involved (see Appendix $A$ ). The first order condition $F(B)$ may be factored into $\left(\lambda / \theta_{1} \theta_{2}\right)\left[\left(1-\theta_{1} \mathrm{~B}\right)\left(1-\theta_{2} \mathrm{~B}\right)\left(1-\theta_{1} \mathrm{~B}^{-1}\right)\left(1-\theta_{2} \mathrm{~B}^{-1}\right)\right]$, where $\theta_{1}$ and $\theta_{2}$ are comlex conjugates vhose value depends on $\lambda$. (These parameters are the zeros 
of $F$ that satisfy $\left|\theta_{i}\right|<1$ ). With this factorization, we can develop a tro sided moving average expression for the grovth component

$$
y_{t}^{g}=\left[\frac{\theta_{1} \theta_{2}}{\lambda}\right]\left[\sum_{j=0}^{\infty}\left[A_{1} \theta_{1}^{j}+A_{2} \theta_{2}^{j}\right] y_{t-j}+\sum_{j=0}^{\infty}\left[A_{1} \theta_{1}^{j}+A_{2} \theta_{2}^{j}\right] y_{t+j}\right]
$$

where the parameters $A_{1}$ and $A_{2}$ depend on $\theta_{1}$ and $\theta_{2}$ in a manner spelled out in Appendix A. It may be shorn that the coefficient $\left[A_{1} \theta_{1}^{j}+A_{2} \theta_{2}^{j}\right]$ is a real number for each $j$ and that $A_{1}$ and $A_{2}$ are complex conjugates. Hence, the grodth component is a tro sided moving averages involving a kind of "double exponential smoothing." Table II-2 indicates the values of the $\theta \mathbf{s}$ and A's

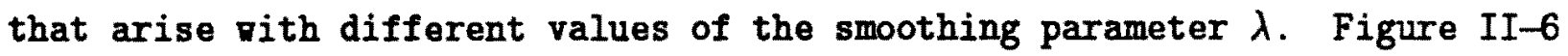
plots the filter veights of the cyclical filter for the $\lambda=1600$ value that has most frequently been employed, folloving Hodrick and Prescott [1980].7

Combining the results of this section, ve conclude that the HP filter vill render stationary series that are integrated (up to fourth order), but that it also removes substantial lov frequency variation. On the other hand, the HP filter vill preserve more lov frequency content than the first difference vhich is commonly employed for the purpose of achieving stationarity. As in the case of the ES filter, this property derives from the fact that the (fourth) differences in the numerator are partly undone by the $\left[\left(1-\theta_{1} B\right)\left(1-\theta_{2} B\right)\left(1-\theta_{1} B^{-1}\right)\left(1-\theta_{2} B^{-1}\right)\right]$ terms vhich appear in the denominator, since the modulus of $\theta_{i}$ is about .9 vith the smoothing parameter $\lambda$ set equal to 1600 . Another way to reach this conclusion is to examine Singleton's [1988, figure 2] comparison of the squared gain of the HP and first difference filter.

TSee Appendix A for a discussion of the rationalization of $\lambda=1600$ from the standpoint of an unobserved components model. 


\section{Comparisons of ES and IP Filters}

There is a single parameter on phich the gain of the ES and HP cyclical filters depends, the smoothing parameter. To compare the filters, ve chose $\lambda=1600$ for the HP cyclical filter and required that the gain of the HP and ES cyclical filters be equal at the frequency $\pi / 16$, which corresponds to a period of 8 years (32 quarters).

The results of this comparison are given in Figure II-7: the HP filter looks more like the ideal filter presented in Figure 2, since its gain function is more nearly zero for frequencies belor $\pi / 16$ and more nearly unity for frequencies above it.

\section{Inverse Optimal Linear Filtering}

Given the form of the HP filter, one can ask "for vhat set of statistical structures is the HP filter an optimal linear filter in the sense of minimizing the mean square error as in Wiener [1949] and Whittle [1963]?"8 We treat this question in Appendix B and summarize here the results of our investigation.

If innovations to the gropth and cyclical components are uncorrelated, ve find that a necessary condition for the HP filtering procedure to be optimal is that the stochastic gropth component have a random valk grovth rate, i.e., that it be second difference stationary in an extension of the Nelson and Plosser [1982] terminology. Hovever, this condition is not sufficient. For the HP filter to be optimal, ve mast further require either that the cycle consist of uncorrelated events or that there be an identical dynamic

8This question vas first posed to us by Kark Watson, who also provided useful hints about hor to proceed with answering the question. Hovever, Hatson should not be held responsible for any potential errors in folloving these leads or for our interpretation of the results. 
mechanism that propagates changes in the grovth rate and innovations to the business cycle component.

In real business cycle models grorth and business cycles do not arise as separate phenomena, so that these models provide no theoretical justification for decomposition into grovth and cycles. The simplest vay to introduce grozth into a real business cycle model is to assume that the level of Harrod-neutral technical progress expands at a constant rate. This induces common deterministic trends into time series and economic fluctuations are stationary stochastic processes about this common trend. In this case there is a clear-cut separation betreen gropth and cycles; grovth is responsible for the common deterministic trend vhile cycles are the fluctuations around that trend. If ve make exogenous technical progress stochasitc and assume that it follors an integrated process (a kind of "stochastic grorth"), then these vill generally set in motion complex responses that may resemble economic fluctuations (see King, Plosser and Rebelo [1988b, Section II]). Thus, it is difficult to separate gropth and fluctuations in this context. The dividing lines virtually disappear in models of endogenous economic grozth, in thich transient displacements to the dynamic system have permanent consequences for the paths of economic quantities (King and Rebelo [1986]). Hovever, given that there are a variety of motivations for filtering-some vhich do not hinge on an interest in precise grovth versus cycle decompositions- $\rightarrow$ next explore the consequences of lor frequency filtering in standard real business cycle models. 


\section{Filtering \& Real Business Cjcle Model}

Our next objective is to investigate hor application of a lor frequency filter influences the time series generated by an artificial economy. The specific economy that ve study is one that re have explored in detail elsewhere (King, Plosser, and Rebelo [1988a]), so that our presentation is deliberately brief. For reference purposes, the economy is close to that studied by Hansen [1985] and Prescott [1986], Dhich contain examples of the application of HP filtering to model and actual time series.

\section{The Basic Neoclassical Model}

The deep structure of the model economy-preferences, technology and resource constraints-is specified as follors:

Preferences: The representative agent values sequences of consumption $\left(\mathrm{C}_{t}\right)$ and leisure $\left(\mathrm{L}_{\mathrm{t}}\right)$ according to

$$
E_{0}\left[\sum_{t=0}^{\infty} \beta^{t} u\left(C_{t}, L_{t}\right)\right],
$$

vhere for simplicity ve vork vith the loglinear momentary utility function $u\left(C_{t}, L_{t}\right)=\log \left(C_{t}\right)+\eta \log \left(L_{t}\right)$. In this expression $E_{0}$ is the expectation conditioned on information available at time zero.

Technology: The production and accumlation technologies are

$$
Y_{t}=A_{t}\left[x_{t}^{1-\alpha}\left(N_{t} x_{t}\right)^{\alpha}\right] \quad \text { and } \quad R_{t+1}=(1-\delta) R_{t}+I_{t}
$$

Dhere $Y_{t}$ is output, $K_{t}$ is labor input, $K_{t}$ is capital, $I_{t}$ is investment and $\delta$ is the rate of depreciation. The production function is constant returns-to-scale $\nabla$ ith $0<\alpha<1$. The exogenous variables are $\mathrm{x}_{t}$, ,hich is a labor augmenting technological shift that satisfies $x_{t+1} / x_{t}=\gamma_{x}>1$, and $A_{t}$, vhich is a stationary total factor productivity shift that satisfies 
$\log \left(A_{t} / \underline{A}\right)=\rho \log \left(A_{t-1} / \underline{A}\right)+\epsilon_{A t}$ with $\underline{A}>0, \rho>0$, and $\epsilon_{t}$ is an iid random variable vith $E\left(\epsilon_{t}\right)=0$ and $E\left(\epsilon_{t}\right)=s_{\epsilon}^{2}$.

Resource Constraints. The resource constraints for goods and leisure are

$$
C_{t}+I_{t}=Y_{t} \quad \text { and } \quad N_{t}+L_{t}=1
$$

Values for technology and preference parameters are given in Table III-1.

\section{Approximate Dynamics}

The equilibrium quantities for consumption, investment, output, capital and real vages vill fluctuate stochastically around a common deterministic trend induced by $x_{t}$. On the other hand, hours are stationary random variables. Approximating this system, ve can develop a state space system for the logarithms of variables so that each variable can be vritten in the form $\log \left(Y_{t}\right)=\log (Y)+\log \left(X_{t}\right)+\dot{y}_{t}$, where $\dot{y}_{t}$ is interpretable as the deviation from trend. The state space system which describes the vector $z_{t}=$ $\left[\begin{array}{llllll}\hat{y}_{t} & \hat{c}_{t} & \dot{i}_{t} & \hat{k}_{t} & \dot{v}_{t} & \hat{N}_{t}\end{array}\right]^{\prime}$ then is :

$$
z_{t}=\Pi s_{t}
$$

vith state evolution governed by

$$
s_{t+1}=M s_{t}+\epsilon_{t+1} \quad \text { and } \quad M=\left[\begin{array}{ll}
\mu_{1} & \pi_{k A} \\
0 & \rho
\end{array}\right],
$$

vhere $s_{t}=\left[\begin{array}{ll}\hat{k}_{t} & \hat{A}_{t}\end{array}\right]$ and $\epsilon_{t}=\left[\begin{array}{ll}0 & \epsilon_{A, t+1}\end{array}\right]$. Coefficients in the matrices $\Pi$ and M-implied by the Table III-1 deep parameters-are given in Table III-2. Stationarity of deviations from trend $\left(\mu_{1}<1\right)$ is assured by diminishing

OOur approximation strategy- -hich vorks off the first order conditions to the representative agent's dynamic optimization problem-is detailed in King [1987] and King, Plosser and Rebelo [1987]. In the present context, it is equivalent to the log linear approximation strategy of Christiano [1988], vhich uses quadratic approximation to the objective function. 
returns to capital (holding fixed labor input). Thus, $s_{t}$ is stationary so long as $A_{t}$ is stationary $(\rho<1)$.

Thus, it is relatively easy to compute the population moments of the economic variables, $z_{t}$ and $s_{t}$, by the tro step procedure common in state space systems. First, one computes the moments of the states and then one exploits the simple relations that are readily shown to exist for moments of the $z$ variables. For example, if $v=E\left(s_{t} s_{t}^{\prime}\right)$ is the variance-covariance matrix of the states, then $E\left(z_{t} z_{t}^{\prime}\right)=\Pi V \Pi^{\prime}$ is the variance of the $z$ variables. Results reported in subsequent tables involve application of these ideas in a straightforward manner.

\section{Filtering the System}

Table III-3 reports the consequences of application of the Hodrick and Prescott [1980] cyclical filter for the population moments of the model. Panel $A$ of the table reports the moments of the original series (i.e., linearly detrended); panel B reports moments of the filtered series.

Looking first at the unfiltered moments in panel A, a researcher would draw one set of conclusions about the relative volatility of different series: labor input is about half as volatile as output; consumption is about tro-thirds as variable; and investment is about trice as variable. The real vage is less volatile than output (about two thirds) but more variable than labor input. Further, one vould conclude that labor input is at best only slightly more procyclical than capital input, on the basis that each has a contemporaneous correlation vith output of about three quarters. Finally, one vould viev the stochastic components of output as relatively persistent given that the correlation of output vith its fourth $\mathrm{lag}_{\mathrm{g}}$ is about .75 and the correlation with its tvelfth lag is about .4. 
Turning nov to panel $B$, one finds the population moments for the components of time series isolated by the HP cyclical filter, vith the smoothing parameter $\lambda$ set to 1600 . Through this filter, a very different picture of business cycles emerges. Consumption is nov only about a quarter as variable as output, labor input is tro thirds as variable and investment is nor nearly three times as variable. The volatility of the real vage is only one sixth that of output. Further, vith an application of the HP filter, the real vage it is sharply less volatile than labor input conly about one half as volatile).

One nov also has a very different picture of cyclical movements in inputs: labor input is very highly correlated vith output (.98) and capital is unrelated to cyclical activity (its correlation is .07). Finally, autocorrelation in output is close to zero at a lag of one year (four quarters) and negative at a lag of three years (tvelve quarters).

Considering the state space system, it is not too hard to see vhat is happening to produce these results. The evolution of all variables depends on their veights placed on the state variables, the capital stock and the technology shock. The technology shock is given by $\dot{A}_{t}=\rho \dot{A}_{t-1}+\epsilon_{A t}$, vhich implies that it is representable as $\bar{A}_{t}=\sum_{s=0}^{\infty} \rho^{s} \epsilon_{A, t-s}$. Given the lav of motion for capital, $\hat{k}_{t+1}=\mu_{1} \dot{k}_{t}+\pi_{k \mathbf{A}} \hat{A}_{t}$ vith $\mu_{1} \simeq .95$, the capital stock is a moving average of technology shocks, with veights that die out very slovly. Relative to the technology shock, then, the capital stock is very slop moving and application of the lov frequency filter down plays its influence and raises that of the technology shock. Notice that this occurs despite the fact that both capital and technology are driven by $\epsilon_{\text {At }}$, since they are related to it by different (one sided) linear filters. 
Figure III-1 shors the impact of HP filtering on the spectral densities of these tro variables (the dashed line is the spectral density of the unfiltered series and the solid line is the spectral density of the filtered series). Despite the fact that both variables display Granger's [1961] typical spectral shape, the poper of the capital stock is more concentrated at 100 frequencies and, consequently, the HP filter domplays its relative influence.

Random Walk Technology Shocks

It is possible to solve this model under the alternative assumption that technology shocks are integrated processes (see Christiano [1988] or King, Plosser and Rebelo [1988b, section 2]). In vied of the Nelson and Plosser [1982] results and given the intuitive idea that technology shocks are vell modeled as a random valk (vith positive drift), ve present some final results based on that alternative specification in Table III-2. Since the levels of variables are not stationary, population moments are not finite. Thus, ve present results for the first difference filter and for the HP cyclical filter. In the presence of this nonstationarity, the HP filter produces results that broadly resemble those of Table III-3, although the shift to a random ralk technology shock does reduce the extent of labor volatility, as stressed by Hansen [1988].

\section{Does Filtering Affect Homents that Are Very Important?}

In viering the foregoing results, one is naturally led to ask vhether the practice of filtering affects moments that are very important from the standpoint of real business cycle research. In this research area, it is established practice to focus on a subset of moments-typically 
contemporaneous correlations and selected autocorrelations or cross correlations-in evaluating vhether an alteration in a model's physical environment is quantitatively important. For example, Hansen's [1985] analysis of the influence of indivisibilities in labor supply on a real business cycle model concentrates on its implications for the contemporaneous covariance matrix of the model's variables, notably the relative volatility of hours and productivity. Clearly, given the foregoing, HP filtering vill alter the moments studied by Hansen. Hodever, no major alteration in one's viers of the importance of this structural change is indicated by a careful comparison of Hansen's [1985] analysis (rhich uses HP filtering) and King, Plosser and Rebelo's [1988a] analysis of a similar economy (rhich does not employ HP filtering).

By contrast, vith complicated model elements that are capitalistic in nature-that is, those which alter intertemporal substitution opportunities-HP filtering is likely to be far more important. To take one example, Rourenhorst [1988] studies the influence of the "time to build" technology of Kydland and Prescott [1982]. He concludes that the major differences betreen models vith and vithout time to build lie in the autocovariances- - ith jumps in othervise smooth generating functions occurring at the lags that are integer multiples of the delay betreen the initiation and fruition of an investment project. The application of a smoothing procedure-such as the HP cyclical filterkey implication of the model. To take another example, there has been recent interest in the cyclical implications of models vith endogenous long run grorth (King and Rebelo [1986], King, Plosser and Rebelo [1988b] and Christiano and Eichenbaum [1988b]). A major feature of these models is the endogenous generation of a stochastic grouth component of the form that is 
eliminated by the HP cyclical filter. He conclude that there are important and numerous extensions of real business cycle models in phich essential information vill be lost if the HP cyclical filter is the unique mechanism for vieving model imlications.

\section{Inplications of Our Analysis for Practice}

To this point, re have provided an exposition and critique of an established practice in real business cycle research, the lon frequency filtering of model and actual time series vith a method due to Hodrick and Prescott [1980]. In our vied, this procedure has gained videspread acceptance for three reasons, which are important background to our recomendations for alterations of research practice. First, as stressed by Hodrick and Prescott [1980, page 1], their method is a simple procedure that can be mechanically applied to economic time series. This characteristic reduces the judgmental decisions by a researcher and thus makes easier the process of cross-investigation comparison which is essential to scientific progress. Second, we have seen that HP cyclical filtering renders stationary series that have persistent changes in the underlying gropth rate. Thus, as stressed by Hodrick and Prescott [1980, pp. 4-5], it is capable of accommodating phenomena such as "the productivity slordonn" in underlying time series. Third, the procedure implements a traditional vied that economic grorth and business cycles are phenomena that are to be studied separately. Further, application of the HP procedure generates summary statistics for real U.S. data that correspond to many economists' prior notions of "business cycle facts."

He not provide some suggestions for hor researchers should modify practice based on the results of our investigation, so as to maximize 
scientific commanication. These suggestions are based on three ideas: (i) it is desirable on statistical grounds to report sample moments only vhen time series have finite population counterparts; (ii) economic models generally contain explicit instructions about hov to transform the data so that it will be stationary; and (iii) since the traditional separation of grovth and business cycles is not an attribute of modern dynamic equilibrium theories, which embody concrete and extensive cross frequency restrictions, economists pursuing the real business cycle research program cannot have sharp priors about the decomposition of macroeconomic time series along these lines.

Reporting Attributes of Dynamic Macroeconomic Models: The moment implications of a dynamic equilibrium model are governed by its reduced form, e.g., the linear dynamic system summarized by the $\Pi$ and $M$ matrices.

Investigators should alvays report sufficient information for calculation of alternative moment implications to be undertaken by another researcher without solution of the model.10

Reporting HP Growth Components: Researchers utilizing the HP filtering procedure should report moments of the actual and model generated "stochastic grovth" components so that comparisons between models can be made on the basis of this information.

First, since the "prior" under the HP filtering procedure is that the actual data contain a stochastic trend, a transformation to achieve stationarity is necessary. Belor, ve report results for the HP stochastic

\footnotetext{
10Although not present in such important contributions as Kydland and Prescott [1982], Hansen [1985], and Prescott [1986], this information is provided in other early rork by Rydland and Prescott [1979] and Long and Plosser [1983] . More recently, this practice is follored by Christiano [1988], Hansen and Sargent [1988], King, Plosser and Rebelo [1988a,b], and Kydland and Prescott [1988] in the recent Journal of Monetary Economics special issue on Real Business Cycles.
} 
growth component extracted from a model filtered vith $(1-B)\left(1-B^{-1}\right) / 2$ for this purpose. We have experimented vith this centered second difference for tro reasons: (i) it induces no phase shift; and, (ii) it renders stationary a time series vith a random valk grovth rate.

Second, the researcher should report statistics on this stochastic grovth component under the transformation implied by the specified dynamic economic model that naturally achieves stationarity: ve give tro examples of this transformation belor.

Reporting Moments for Model Based Data Transformations: Dynamic stochastic economic models generally suggest rays of treating nonstationarity in economic time series. Any investigation should at minimum report the direct transformations suggested by the model, since evidence against this transformation is useful in judging the adequacy of the model.

Trend Stationary Models: For example, one common model building strategy is to vier economic time series as stationary relative to a common deterministic trend, as is implicit in Hansen [1985] and explicit in King, Plosser and Rebelo [1988a]. Under this scenario, our results suggest that HP filtering can dramatically alter hov a researcher vievs a model economy as vorking, for example in terms the relative importance of variation in capital and labor in response to persistent but stationary technology shocks. Major components of time series on output, consumption etc. are treated by the filter as stochastic grovth, when the posited model involves none. He recomend tro alterations in practice for this case. First, researchers should report unfiltered moment implications as vell as HP filtered moment implications. Researchers using the HP filter should also report attributes of the isolated stochastic grovth components, under the model's assumption that these are stationary and the alternative assumption that there is a 
random valk grovth rate, vhich is implicit in analysis underlying HP filtering. In table IV.1, ve provide an application of these methods to the population moments of the model economy described in section III above. These tables make clear that there is a substantial component of the time series removed by the HP filter and that this component in many ways resemble those of the unfiltered series. Thus, in such a trend stationary model, a much clearer picture of the operation of the theoretical model is provided by table III-3, panels A\&B, and table IV-1, panels A\&B, than by individual components. 11

Presumably, it is not feasible to report all of the information in the tables ve have presented here, given constraints on journal space. But it would be very easy to add information on HP growth components to our table I-1, which is a standard device for reporting implications of business cycle models.

Stochastic Trend Yodels: Frequently, lov frequency filtering is motivated by concern over potential nonstationarity of macroeconomic time series as suggested, for example, by Nelson and Plosser's [1982] investigation of individual series and King, Plosser, Stock and Watson's [1987] investigation of common stochastic trends. For models vith explicit stochastic grovth elements-as in, for example, Christiano [1988], Hansen [1988] and King, Plosser and Rebelo [1988b] -it vill generally not be meaningful to produce simulated moments for the levels of economic variables, since the population counterparts are not finite. Some transformation of

MFurther, in such trend stationary environments, we caution that research vhich focuses on dynamic elements of model construction-like that of Rouvenhorst (1988) discussed earlier-should be vary of interpreting HP filtered moments as providing much information about the importance of structural changes. 
actual and model generated data $\nabla i l l$ be necessary: tro natural transformations that are consistent vith the economic structure of stochastic steady state models are first differencing and construction of ratios of variables possessing common stochastic trends. Motivated by concern over nonstationarity, some recent investigations do undertake exploration of model sensitivity to filtering and data transformation in the way that our investigation suggests. Examples are provided in Christiano and Eichenbaum [1988a], tho explore HP filtering and first differencing, and King, Plosser and Rebelo [1988b], who use first difference filtering and a ratio form that involves imposition of a common stochastic trend. Again, for researchers using HP filtering, our recommended practice requires reporting of statistics on stochastic grovth components under (i) the model based assumption that the first difference is stationary and (ii) using the second difference filter discussed earlier.

No real business cycle research to this point has explicitly incorporated the persistent changes in productivity gronth originally cited by Hodrick and Prescott [1980] as a major motivation for application of their filter to post var U.S. data. This feasible investigation could vell shed further light on the interaction of grovth and business cycles.

\section{Sumary and Conclusions}

This paper has reported on implications of lor frequency filtering, focusing on the HP filter-due to Hodrick and Prescott [1980]commonly used in investigations of the stochastic properties of real business cycle models.

First, application of the filter to U.S. real gross national product and a measure of labor input illustrates the impact of HP filtering on the 
character of cyclical components. Second, re derive convenient expressions for the HP filter and the closely related exponential smoothing (ES) filter in forms appropriate for both the time domain and frequency domain. These results are used (i) to discuss the influence of smoothing parameters and (ii) to demonstrate that the cyclical components phich these filters generate are stationary, when the underlying time series are differenced stationary stochastic processes in the sense of Nelson and Plosser [1982]. Third, ve consider the conditions under vhich the HP filter is the optimal linear filter in the sense of Wiener [1949] and Whittle [1963]. These conditions are unlikely to be even approximately true in practice. Fourth, application of the HP filter to a basic real business cycle model demonstrates that this filter substantially influences the perception of the operation of the model economy, as viered by researchers studying its moment implications. Fifth, based on the results of our investigations, re recomend some ner practices designed to facilitate scientific communication betreen researchers.

At the end of our investigation, horever, ve remain struck by the Figures presented in section 1: macroeconomic research focusing on the component of the time series that is isolated by the HP cyclical filter-in terms of either devising stylized facts or evaluating dynamic economic models-is likely to capture only a subset of the time series variation that most economists associate with cyclical fluctuations. A major facet of our ongoing research is the construction of dynamic models that more completely integrate the explanation of these components. 


\section{References}

Baxter, Marianne, [1988] "Business Cycles and the Exchange Rate Regime: Some Evidence from the United States," Rochester Center for Economic Research rorking paper \#169.

Baxter, Marianne and Alan Stockman, [1988] "Business Cycles and the Exchange Rate Regime: Some International Evidence," forthcoming in Journal of Monetary Economics, September 1989.

Bell, W., [1984] "Signal Extraction for Non-Stationary Time Series," Annals of Statistics $12,646-684$.

Brovn, R., [1962] Smoothing, Forecasting and Prediction of Discrete Time Series. Prentice Hall, Englevood Cliffs, Ner Jersey.

Burns, Arthur and Wesley C. Mitchell, [1941] Keasuring Business Cycles, Nen York, National Bureau of Economic Research.

Christiano, Larrence, [1988] "Why does Inventory Investment Fluctuate So Much?" Journal of Monetary Economics, 21, No. 2/3, 247-280.

Christiano, Lawrence and Martin Eichenbaum, [1988a] "Is Theory Really Ahead of Business Cycle Measurement?" National Bureau of Economic Research vorking papers, \#2700.

Christiano, Larrence and Martin Eichenbaum, [1988b] "Human Capital, Endogenous Grovth, and Aggregate Fluctuations," Northrestern University vorking paper.

Fishman, George, [1969] Spectral Methods in Econometrics, Cambridge, Harvard University Press.

Friedman, Milton, [1957] A Theory of the Consumption Function, Princeton, N.J. : Princeton University Press

Granger, Clive, [1961] "The Typical Spectral Shape of An Economic Variable," Econometrica, vol 37, no. 3, pp. 424-438.

Hansen, Gary, [1985] "Indivisible Labor and the Business Cycle," Journal of Monetary Economics 16, 309-27.

Hansen, Gary, [1988] "Technical Progress and Aggregate Fluctuations", U.C.L.A. vorking paper.

Hansen, Gary, and Thomas J. Sargent, [1988] "Straight Time and Over Time in General Equilibrium," Journal of Konotary Economics $21: 2 / 3,281-308$.

Harvey, Andren, [1981] Time Series Models, Oxford: Phillip Allan. 
Hodrick, Robert and Edward Prescott, [1980] "Post-War U.S. Business Cycles: An Empirical Investigation," vorking paper, Carnegie-Mellon University.

King, Robert G. and Charles I. Plosser, [1989] "Real Business Cycles and the Test of the Adelmans," University of Rochester.

King, Robert G., C.I. Plosser and S.T. Rebelo, [1988a] "Production, Gronth, and Business Cycles: I. The Basic Heoclassical Model," Journal of Monetary Economics 21:2/3, 195-232.

King, Robert G., C.I. Plosser and S.T. Rebelo, [1988b] "Production, Grovth, and Business Cycles: II. Mer Directions," Journal of Monetary Economics $21: 2 / 3,309-342$.

King, Robert G., C.I. Plosser and S.T. Rebelo, [1987] "Production, Grovth, and Business Cycles: Technical Appendix," University of Rochester manuscript.

King, Robert, Charles Plosser, James Stock, and Mark Watson, [1987] "Stochastic Trends and Economic Fluctuations," Rochester Center for Economic Research Working Paper \#79.

Ring, Robert G. and Sergio.T. Rebelo, [1986] "Business Cycles rith Endogenous Grovth," University of Rochester manuscript.

Koopmans, Leonid, [1974] The Spectral Analysis of Time Series, Ner York: Academic Press.

Kuznets, Simon, [1930] Secular Movements in Production and Prices, Boston: Houghton Mifflin.

Kuznets, Simon, [1961], Capital and the American Economy: Its Formation and Financing, National Bureau of Economic Research.

Kydland, Finn and Edward Prescott, [1979] "A Competitive Theory of Fluctuations and the Feasibility and Desirability of Stabilization Policy," in S.Fischer, ed., Rational Expectations and Economic Policy, Chicago: University of Chicago Press.

Kydland, Finn and Edvard Prescott, [1982] "Time to Build and Aggregate Fluctuations," Econometrica 50, 1345-70.

Kydland, Finn and Edward Prescott, [1988], "The Work Week of Capital and Its Cyclical Implications," Journal of Nonetary Economics, 21:2/3, 343-360.

Long, John and Charles Plosser, [1983] "Real Business Cycles," Journal of Political Economy 91, 1345-70.

McCallum, Bennett, [1989] "Real Business Cycles," in Robert Barro (ed.), Handbook of Yodern Business Cycle Theory, Nev York: Wiley.

Mitchell, Wesley C., [1927] Business Cycles: The Problem and Its Setting, Ner York: National Bureau of Economic Research. 
Mitchell, Nesley C., [1951] That Happens During Business Cycles, Ner York, National Bureau of Economic Research.

Helson, Charles and Charles Plosser, [1982] "Trends and Random Walks in Hacroeconomic Time Series," Journal of Monetary Economics 10, 139-67.

Prescott, Edward, [1986] "Theory thead of Business Cycle Measurement," Carnegie-Rochester Conference Series on Public Policy 25, 11-66.

Rouvenhorst, Geert, [1988] "Time to Build and Aggregate Fluctuations: A Reconsideration," University of Rochester, processed manuscript

Singleton, Kenneth, [1988] "Econometric Issues in the Analysis of Equilibrium Business Cycle Models," Journal of Monetary Economics, 21, 361-386.

Watson, Mark, [1986], "Univariate Detrending Methods vith Stochastic Trends," Journal of Monetary Economics, 18, 49-76.

Whittle, Peter, [1963] Prediction and Regulation, Princeton, N.J.: Van Nostrand.

Wiener, Norbert, [1949] Extrapolation. Interpolation and Smoothing of Stationary-Time-Series, New York: J. Wiley Sons. 


\section{Lppendix A}

Analysis of the HP Filter in Time Domain

The starting point for our analysis is the (first order condition) requirement that

$$
y_{t}=F(B) y_{t}^{g}
$$

vhere $F(B)=\lambda\left[B^{-2}-4 B^{-1}+\left(6+\frac{1}{\lambda}\right)-4 B+B^{2}\right]$.

$$
=\lambda\left[(1-B)^{2}\left(1-B^{-1}\right)^{2}+\frac{1}{\lambda}\right] .
$$

\section{A.1. Zeros of F Polynomial}

We develop properties of the polynomial $F(z)$, especially the location of its zeros, establishing the claims made in the main text.

(a) Reciprocal Character of Roots - since the polynomial F(z) is symmetric if $z^{*}$ is a root then $1 / z^{*}$ is also a root. To see this, note that $F(z)=$ $\lambda\left[(1-z)^{2}\left(1-\frac{1}{z}\right)^{2}+\frac{1}{\lambda}\right]$ for arbitrary $z$. Thus, if $z^{*}$ implies $F\left(z^{*}\right)=\lambda\left[\left(1-z^{*}\right)^{2}\left(1-\frac{1}{z}\right)^{2}+\frac{1}{\lambda}\right]=0$ then $F\left(1 / z^{*}\right)=$ $\lambda\left[\left(1-1 / \mathrm{z}^{*}\right)^{2}\left(1-\mathrm{z}^{*}\right)^{2}+\frac{1}{\lambda}\right]=\mathrm{F}\left(\mathrm{z}^{*}\right)=0$.

(b) Complex Character of Roots - For any real number z, $F(z)>0$. Thus, the roots must be complex. Further, it follors that $z^{*}$ and $1 / z^{*}$ are cormlex conjugates . 


\section{A.2. Inverting $F(B)$ and Related Matters}

The previous results imply that ve can express $F(B)$ as:

$$
F(B)=\left(\lambda / \theta_{1} \theta_{2}\right)\left(1-\theta_{1} B\right)\left(1-\theta_{2} B\right)\left(1-\theta_{1} B^{-1}\right)\left(1-\theta_{2} B^{-1}\right),
$$

Dhere $\left|\theta_{i}\right|<1$, for $i=1,2$.

Thus to determine a useful form for $[F(B)]^{-1}=G(B)$, it is necessary to decompose

$$
\begin{gathered}
\frac{1}{1-\theta_{1} z} \frac{1}{1-\theta_{2} z} \frac{1}{1-\theta_{1} z^{-1}} \frac{1}{1-\theta_{2} z^{-1}} \\
\text { into } A_{0}+\frac{A_{1}}{1-\theta_{1} z}+\frac{A_{2}}{1-\theta_{2} z}+\frac{A_{3}}{1-\theta_{1} z^{-1}}+\frac{A_{4}}{1-\theta_{2} z^{-1}} .
\end{gathered}
$$

To determine $A_{0}, A_{1}, A_{2}, A_{3}$ and $A_{4}$ ve require that

$$
\begin{aligned}
1= & A_{0}\left(1-\theta_{1} z\right)\left(1-\theta_{2} z\right)\left(1-\theta_{1} z^{-1}\right)\left(1-\theta_{2} z^{-1}\right) \\
& +A_{1}\left(1-\theta_{2} z\right)\left(1-\theta_{1} z^{-1}\right)\left(1-\theta_{2} z^{-1}\right)+A_{2}\left(1-\theta_{1} z\right)\left(1-\theta_{1} z^{-1}\right)\left(1-\theta_{2} z^{-1}\right) \\
& +A_{3}\left(1-\theta_{1} z\right)\left(1-\theta_{2} z\right)\left(1-\theta_{2} z^{-1}\right)+A_{4}\left(1-\theta_{1} z\right)\left(1-\theta_{2} z\right)\left(1-\theta_{1} z^{-1}\right) .
\end{aligned}
$$

Evaluating this expression at $z=1$ yields

$$
\frac{1}{1-\theta_{1}} \frac{1}{1-\theta_{2}} \frac{1}{1-\theta_{1}} \frac{1}{1-\theta_{2}}=A+\frac{A_{1}}{1-\theta_{1}}+\frac{A_{2}}{1-\theta_{2}}+\frac{A_{3}}{1-\theta_{1}}+\frac{A_{4}}{1-\theta_{2}}
$$


Evaluating this expression at $z=1 / \theta_{1}$ yields

$$
A_{1}=\left[\left(1-\theta_{2} / \theta_{1}\right)\left(1-\theta_{1}^{2}\right)\left(1-\theta_{2} \theta_{1}\right)\right]^{-1}
$$

and evaluating at the other roots yields

$$
\begin{aligned}
& A_{2}=\left[\begin{array}{lll}
\left(1-\theta_{1} / \theta_{2}\right) & \left(1-\theta_{1} \theta_{2}\right) & \left(1-\theta_{2}^{2}\right)
\end{array}\right]^{-1} \\
& A_{3}=\left[\left(1-\theta_{1}^{2}\right)\left(1-\theta_{1} \theta_{2}\right)\left(1-\theta_{2} / \theta_{1}\right)\right]^{-1} \\
& A_{4}=\left[\left(1-\theta_{1} \theta_{2}\right)\left(1-\theta_{2}^{2}\right)\left(1-\theta_{1} / \theta_{2}\right)\right]^{-1} .
\end{aligned}
$$

Some useful properties of these expressions are as follors. First, $A_{1}=A_{3}$ and $A_{2}=A_{4}$. Second, $A_{1}$ and $A_{2}$ are complex conjugates, as is most readily evident if pe move to the (polar form) representation $\theta_{1}=\operatorname{rexp}(\mathrm{im})$ and $\theta_{2}=$ rexp (-im). Then, when ve substitute these expressions for $\theta_{1}$ and $\theta_{2}$ into the preceding expressions for $A_{1}$ and $A_{2}$, $\nabla e$ find that:

$$
\begin{aligned}
& A_{1}=\left[(1-\exp (-2 i m))\left(1-r^{2} \exp (2 i m)\right)\left(1-r^{2}\right)\right]^{-1} \\
& A_{2}=\left[(1-\exp (2 i m))\left(1-r^{2} \exp (-2 i m)\right)\left(1-r^{2}\right)\right]^{-1},
\end{aligned}
$$

so that the conjugate status of these coefficients becomes clear. Hence, combining the results of the foregoing, ve can express the gropth filter as 


$$
\begin{aligned}
G(B) & =[F(B)]^{-1} \\
& =\left[\frac{\theta_{1} \theta_{2}}{\lambda}\right]\left\{A_{0}+\left[\frac{A_{1}}{1-\theta_{1} B}+\frac{A_{2}}{1-\theta_{2} B}\right]+\left[\frac{A_{1}}{1-\theta_{1} B^{-1}}+\frac{A_{2}}{1-\theta_{2} B^{-1}}\right]\right\} .
\end{aligned}
$$

\section{A.3 Coefficients in the Gronth Filter}

To establish that the coefficients in the grovth filter - which depend $A_{1} \theta_{1}^{j}+A_{2} \theta_{2}^{j}$ for $j \geq 0$ - are real, it is again convenient to adopt the polar form representation

$$
\begin{array}{ll}
\theta_{1}=r \exp (\mathrm{im}) & \theta_{2}=\mathrm{r} \exp (-\mathrm{im}) \\
\mathrm{A}_{1}=\mathrm{R} \exp (\mathrm{iM}) & \mathrm{A}_{2}=\mathrm{R} \exp (-\mathrm{iM}) .
\end{array}
$$

Then, it follors that

$$
\begin{aligned}
{\left[A_{1} \theta_{1}^{j}+A_{2} \theta_{2}^{j}\right] } & =R r^{j} \exp (i(M+j m))+R r^{j} \exp (-i(M+j m)) \\
& =2 R r^{j} \cos (M+j m) .
\end{aligned}
$$


Thus, ve can vrite $G(B)=\sum_{j=-\infty}^{\infty} g_{j} B^{j}$ as

$$
\begin{gathered}
=\left[\frac{r^{2}}{\lambda}\right]\left\{A_{0}+2 R \sum_{j=0}^{\infty} r^{j} \cos (M+j m) B^{j}\right. \\
\left.+2 R \sum_{j=0}^{\infty} r^{j} \cos (M+j m) B^{-j}\right\}
\end{gathered}
$$

which indicates that the roots are real. Further, using $\cos (j m+M)=$ $[\cos (m j) \cos (M)-\sin (m j) \sin (M)]$ it is direct to establish the form of the filter provided by Hodrick and Prescott [1980] and Singleton [1988]. For this purpose, ve note that $A_{0}$ turns out to be $-2 R \cos (K)$. Then, the previous expression for $G(B)$ may be vritten as:

$$
G(B)=\sum_{j=-\infty}^{\infty} g_{j} B^{j}
$$

vhere

$$
\begin{array}{cl}
\qquad g_{j}=r^{j}\left[a_{1} \cos (b j)+a_{2} \sin (b j)\right] & \text { for } j \geq 0 \\
g_{j}=g_{-j} & \text { for } j \leq 0 \\
\text { with the constants } a_{1}=\left[r^{2} / \lambda\right] 2 R \cos (M), & a_{2}=\left[r^{2} / \lambda\right] 2 R \sin (M), \quad b=|m| .
\end{array}
$$




\section{Appendix B}

\section{Inverse Optimal Linear Filtering}

Taking as given a specific filter, the Hodrick and Prescott [1980] filter in our context-one can ask what the implicit model for the underlying time series must be for this filter to be optimal in the sense of minimizing the mean square error as in Viener [1949] and Whittle [1963]. In order to be possible for the HP filter to be optional ve start vith a statistical representation of the underlying time series vhich is linear and in vhich growth and cycles are separate phenomena.

Suppose that re vier the grovth and cyclical components as being generated by ARMA models,

$$
\begin{aligned}
& A^{g}(B) y_{t}^{g}=M^{B}(B) \epsilon_{t}^{g} \\
& A^{c}(B) y_{t}^{c}=M^{c}(B) \epsilon_{t}^{c}
\end{aligned}
$$

where $\epsilon_{t}^{g}$ and $\epsilon_{t}^{c}$ are white noise processes whose variances are $s^{2}\left(\epsilon^{c}\right)$ and $s^{2}\left(\epsilon^{g}\right)$. By assumption, the roots of the autoregressive polynomials lie outside the unit circle (stationarity) and the roots of the moving average polynomial lie outside the unit circle (invertibility). The innovations $\epsilon_{t}^{g}$ and $\epsilon_{t}^{c}$ are serially uncorrelated and, for simplicity, we assume that $E\left[\epsilon_{t}^{g} \epsilon_{t}^{c}\right]=$ 0 . Further, for convenience, ve define the ratio of variances $\psi=$ $s^{2}\left(\epsilon^{c}\right) /\left[s^{2}\left(\epsilon^{c}\right)+s\left(\epsilon^{g}\right)\right]$.

Whittle [1963, chapter V] shors that the optimal (tro sided) signal extraction filter for the cyclical component is: 


$$
C^{*}(B)=\frac{\Gamma_{c c}(B)}{\Gamma_{c c}(B)+\Gamma_{g B}(B)}
$$

where $\Gamma_{c c}(B)$ is the autocovariance generating function of the cyclical component and $\Gamma_{\mathbf{g g}}(B)$ is the autocovariance generating function of the grosth component. From the ARMA structure it follows directly that

$$
\begin{aligned}
& \Gamma_{C C}(z)=\frac{M^{C}(z) M^{C}\left(z^{-1}\right)}{A^{C}(z) A^{c}\left(z^{-1}\right)} s^{2}\left(\varepsilon_{t}^{C}\right) \\
& \Gamma_{g G}(z)=\frac{M^{g}(z) M^{g}\left(z^{-1}\right)}{A^{g}(z) A^{g}\left(z^{-1}\right)} s^{2}\left(\epsilon_{t}^{g}\right)
\end{aligned}
$$

Hence, it follors that the optimal filter may be expressed as:

$$
C^{*}(B)=\frac{\psi A^{B}(B) A^{B}\left(B^{-1}\right)}{\psi A^{B}(B) A^{B}\left(B^{-1}\right)+(1-\psi) Q(B)}
$$

where $Q(B)=\left[A^{C}(B) A^{C}\left(B^{-1}\right)\right]\left[M^{g}(B) M^{g}\left(B^{-1}\right)\right] /\left[M^{C}(B) M^{C}\left(B^{-1}\right)\right]$.

Whittle's analysis [1963] is limited to stationary ARMA processes. Hovever, recent vork extends these formulas to cases vith unit roots (Watson [1986] provides a brief sumary of Bell's [1984] vork on these cases).

\section{Matching the HP Cyclical Filter}

The HP cyclical filter may be written as

$$
C(B)=[F(B)-1]\left[F(B)^{-1}\right]=\frac{\lambda[1-B]^{2}\left[1-B^{-1}\right]^{2}}{1+\lambda[1-B]^{2}\left[1-B^{-1}\right]^{2}}
$$

The problem is to find AR and MA polynomials $\left(A^{g}(B), A^{C}(B), M^{B}(B)\right.$, and $\left.M^{C}(B)\right)$ such that $C(B)$ and $C^{*}(B)$ coincide.

One example of such an inverse optimal filtering rule is discussed by Hodrick and Prescott [1980, page 5] and involves assuming that 


$$
\begin{aligned}
& A^{g}(B)=(1-B)^{2} \\
& A^{C}(B)=M^{G}(B)=K^{C}(B)=1
\end{aligned}
$$

That its, under this specification, the change in the grovth rate is a vhite noise as is the cyclical component. Further, the parameter $\lambda$ corresponds to $\psi /(1-\psi)$ vhich is equal to the ratio of variances $\lambda=s^{2}\left(\varepsilon^{c}\right) / s^{2}\left(\epsilon^{g}\right)$ or $\lambda^{(1 / 2)}=s\left(\epsilon^{c}\right) / s\left(\epsilon^{g}\right)$. Hodrick and Prescott [1980] use a "prior viev that a five percent cyclical component is moderately large as is a one-eighth of one percent change in the rate of grouth in a quarter. This led us to select or $\lambda^{(1 / 2)}=5 /(1 / 8)$ or $\lambda=1600$ as a value for the smoothing parameter." Pursuing this line further, suppose that ve require that $A^{B}(B)=(1-B)^{2}$ so as to accomodate nonstationarity in the grouth rate. Then, it follows that $C(B)=C^{*}(B)$ requires that

$$
\frac{1}{\lambda}=\left(\frac{1-\psi}{\psi}\right) Q(B)
$$

Thus, the optimality of the HP filter requires-apart from the constant terms-implies restrictions across the $A^{C}(B), M^{C}(B)$, and $\mathbb{M}^{B}(B)$ polynomials. In particular, it requires that

$$
M^{C}(B)=\left[\frac{\lambda(1-\psi)}{\psi}\right]^{(1 / 2)} A^{C}(B) M^{B}(B)
$$

In our vier, these sorts of restrictions are unlikely to arise directly from the structure of dynamic economic models since in these models grovth and cycles do not tend to arise as separate phenomena. 
Table I-1

EFFECTS OF FILTERING ON SELECTED POPULATION MOMEITS: BASIC MEOCLASSICAL MODEL.

\begin{tabular}{|c|c|c|c|c|c|c|}
\hline \multirow[b]{2}{*}{ Variable } & \multicolumn{3}{|c|}{ Deviations from Linear Trend } & \multicolumn{3}{|c|}{ Deviations from HP Trend } \\
\hline & Std. Dev. & $\begin{array}{l}\text { Relative } \\
\text { Std. Dev. }\end{array}$ & $\begin{array}{l}\text { Correlation } / \\
\text { Cyclical Output }\end{array}$ & Std. Dev. & $\begin{array}{l}\text { Relative } \\
\text { Std. Dev. }\end{array}$ & $\begin{array}{l}\text { Correlation } \nabla / \\
\text { Cyclical Output }\end{array}$ \\
\hline$\overline{\text { Output }}$ & 4.26 & 1.00 & 1.00 & 2.07 & 1.00 & 1.00 \\
\hline Consurption & 2.73 & 0.64 & 0.82 & 0.53 & 0.26 & 0.78 \\
\hline Investmant & 9.82 & 2.31 & 0.92 & 6.08 & 2.94 & 0.72 \\
\hline Hours & 2.04 & 0.48 & 0.79 & 1.35 & 0.65 & 0.98 \\
\hline Real Vage & 2.92 & 0.69 & 0.90 & 0.79 & 0.17 & 0.59 \\
\hline Capital Stock & 3.74 & 0.88 & 0.73 & 0.68 & 0.28 & 0.07 \\
\hline
\end{tabular}

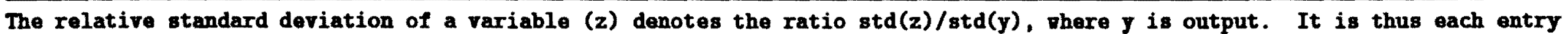
in the standard deviation colum divided by the first entry.

$\operatorname{man} 8901: t 1$ 
Table I-2

Output and Hours, 1948.1-1987.4

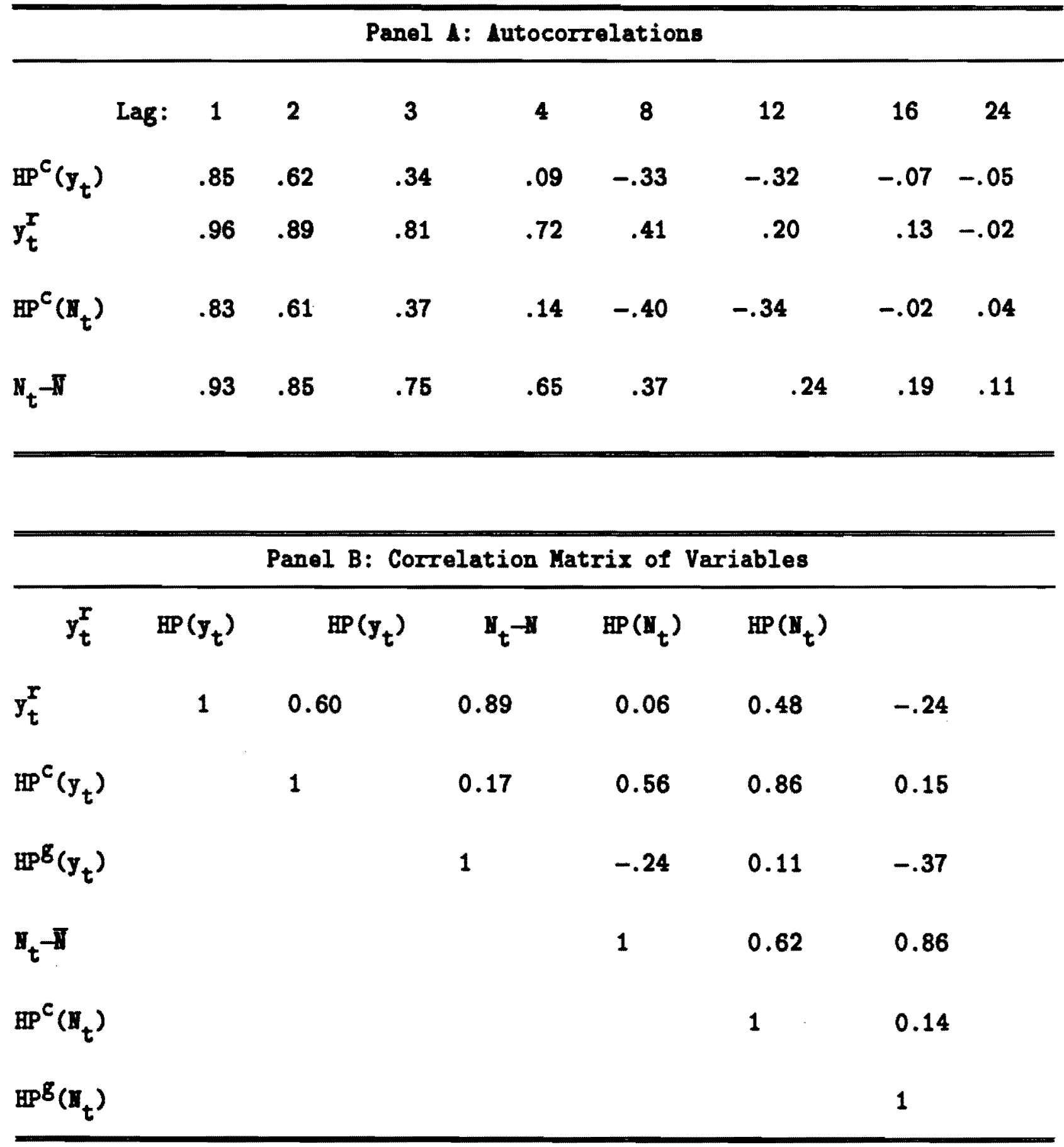


Table I-2(cont'd)

\begin{tabular}{|c|c|c|c|c|c|}
\hline$y_{t}^{r}$ & $\operatorname{HP}^{c}\left(y_{t}\right)$ & $\operatorname{HP}^{\mathrm{B}}\left(\mathbf{y}_{t}\right)$ & $y_{t}-z^{\prime}$ & $\mathbb{H P}^{c}\left(\mathbb{H}_{t}\right)$ & $\operatorname{HP}^{\mathrm{B}}\left(\mathrm{N}_{t}\right)$ \\
\hline .043 & .020 & .035 & .030 & .016 & .024 \\
\hline
\end{tabular}

Notes :

1: The data employed in this table and Figures 1-5 are quarterly U.S. time series over 1948.1-1987.4 constructed from entries in CITIBASE. GNP refers to U.S. real gross national product in 19982 base (CITIBASE code GIP82). The hours percapita series is constructed as follovs: First, monthly series on civilian noninstitutional population 16 years and older (CITIBASE code D16); total porkers (CITIBASE code LHEM); and average veekly hours (CITIBASE code LHCH) vere obtained on a monthly basis. Second, percapita hours at the monthly frequency (N) vas formed as $\mathrm{N}=\mathrm{LHCH} * \mathrm{LHEM} / \mathrm{D} 16$. Third, the monthly entries vere averaged to form quarterly average hours per capita.

\#2: Although ve report moments for the grovth component of the series, this information has to be interpreted vith caution, since despite the fact that a linear trend has been removed prior to filtering, the grorth components may be nonstationary.

$\operatorname{man} 8901: t 2$ 
Table II-1:

\begin{tabular}{cc}
\hline Impact of Smoothing Parameter $(\lambda)$ on Exponential Swoothing Parameter $(\theta)$ \\
\hline$\lambda$ & $\theta$ \\
7.5 & 0.6955 \\
15.0 & 0.7730 \\
30.0 & 0.8333 \\
60.0 & 0.8790 \\
120.0 & 0.9128 \\
240.0 & 0.9375 \\
480.0 & 0.9654 \\
960.0 & 0.9682 \\
\hline
\end{tabular}
man8901:tII1 
Table II-2:

Impact of Smoothing Parameter $(\lambda)$ on Parameters of the HP Filter

\begin{tabular}{rcccc}
\hline$\lambda$ & $\operatorname{re}\left(\theta_{1}\right)$ & $\operatorname{in}\left(\theta_{1}\right)$ & $\operatorname{re}\left(\Lambda_{1}\right)$ & $\operatorname{im}\left(\Lambda_{1}\right)$ \\
100 & 0.7792 & 0.1764 & 0.0566 & 0.0552 \\
400 & 0.8429 & 0.1341 & 0.0398 & 0.0393 \\
1600 & 0.8885 & 0.0997 & 0.0280 & 0.0279 \\
6400 & 0.9211 & 0.0729 & 0.0198 & 0.0197 \\
\hline
\end{tabular}

notes :

(i) $r e\left(\theta_{1}\right)$ is the real part of $\theta_{1}$ and $i m\left(\theta_{1}\right)$ is the imaginary part of $\theta_{1}$.

(ii) since each pair $\theta_{1}, \theta_{2}$ and $\Lambda_{1}, \Lambda_{2}$ are complex conjugates, it suffices to report the real and imaginary parts of each since, for example, $\theta_{2}=\operatorname{re}\left(\theta_{1}\right)-\operatorname{im}\left(\theta_{1}\right)$.

$\operatorname{man} 8901:$ tII2 
Table III-1:

Economic Parameter Values

Depreciation rate:

$\delta=.025$

Labor's share

$\alpha=.58$

Gross grouth rate:

$r_{x}=1.004$

Discount factor:

$\beta=1 /(1+.016)$

Steady state fraction

of time spent vorking*:

I $=.20$

Technology persistence parameter

$\rho=.9$

Standard Deviation of

Technology Innovation $\quad \mathrm{s}^{2}(\epsilon)=1.00$

It is equivalent for us to specify the steady state fraction or the utility parameter $\eta$, since there is a simple relation that links these tro parameters.

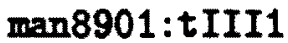


Table III-2:

\section{Paraneters of the Log-linear Sjsten}

\begin{tabular}{|c|c|c|}
\hline \multirow[b]{3}{*}{ Consumption } & \multicolumn{2}{|c|}{ State Variable: } \\
\hline & Capital & Technology Shock \\
\hline & $\pi_{c k}=.617$ & $\pi_{C \Lambda}=.298$ \\
\hline Labor Input & $\pi_{I \mathbf{I}}=-.294$ & $\pi_{\mathrm{HA}}=1.048$ \\
\hline Investment & $\pi_{i k}=-.629$ & $\pi_{i 1}=4.733$ \\
\hline Output & $\pi_{y k}=.249$ & $\pi_{y \Lambda}=1.608$ \\
\hline Real Wage & $\pi_{\text {vk }}=.544$ & $\pi_{\nabla \Lambda}=.560$ \\
\hline Capital Stock & $\mu_{1}=.953$ & $\pi_{k A}=.137$ \\
\hline
\end{tabular}

$\operatorname{man} 8901:$ tIII2 
Table III-3

EFFECTS OF FILTERING ON POPULATION MOHEATS

\begin{tabular}{|c|c|c|c|c|c|c|c|c|c|c|c|c|c|c|c|c|}
\hline \multirow[b]{2}{*}{ Variable } & \multirow{3}{*}{$\begin{array}{c}\text { Std. } \\
\text { Deriation }\end{array}$} & \multirow{2}{*}{$\begin{array}{l}\text { Std. Dev. } \\
\text { Relative } \\
\text { to } \overline{\mathbf{y}}\end{array}$} & \multicolumn{3}{|c|}{ Autocorrelations } & \multicolumn{11}{|c|}{ Cross-correlations vith $\bar{J}_{t-j}$} \\
\hline & & & 1 & 2 & 3 & 12 & 8 & 4 & 2 & 1 & 0 & -1 & -2 & -4 & -8 & -12 \\
\hline \multicolumn{16}{|c|}{ Panel 1: Moments of 0riginal Series } & \\
\hline$\dot{\mathbf{y}}$ & 4.26 & 1.0 & .93 & .86 & .80 & .42 & .65 & .74 & .86 & .93 & 1.0 & .93 & .86 & .74 & .65 & .42 \\
\hline$\hat{\mathbf{c}}$ & 2.73 & .64 & .99 & .98 & .97 & .76 & .82 & .86 & .85 & .84 & .82 & .76 & .71 & .61 & .47 & .36 \\
\hline$\hat{\mathbf{i}}$ & 9.82 & 2.31 & .88 & .77 & .67 & .11 & .26 & .52 & .70 & .80 & .92 & .85 & .79 & .68 & .60 & .38 \\
\hline$\dot{\mathbf{n}}$ & 2.04 & .48 & .86 & .73 & .62 & -.11 & .04 & .32 & .52 & .65 & .79 & .73 & .67 & .67 & .42 & .31 \\
\hline i & 2.92 & .69 & .98 & .96 & .94 & .69 & .78 & .85 & .88 & .90 & .90 & .84 & .78 & .67 & .61 & .39 \\
\hline$\dot{i}$ & 2.29 & .54 & .90 & .81 & .73 & .28 & .42 & .64 & .80 & .88 & .98 & .91 & .84 & .72 & .64 & .40 \\
\hline$i$ & 3.74 & .88 & 1.00 & .99 & .98 & .81 & .85 & .82 & .77 & .73 & .68 & .63 & .69 & .61 & .39 & .30 \\
\hline$\dot{\mathbf{r}}$ & 0.11 & .03 & .87 & .76 & .66 & -.47 & -.34 & -.07 & .14 & .28 & .43 & .40 & .36 & .30 & .22 & .16 \\
\hline
\end{tabular}


Table III-3 (Continued)

EFFECTS OF FILTERING ON POPULATION MOMENTS

\begin{tabular}{|c|c|c|c|c|c|c|c|c|c|c|c|c|c|c|c|c|}
\hline \multirow[b]{2}{*}{ Variable } & \multirow{2}{*}{$\begin{array}{c}\text { Std. } \\
\text { Deriation }\end{array}$} & \multirow{2}{*}{$\begin{array}{c}\text { Std. Der. } \\
\text { Relative } \\
\text { to } \bar{y}\end{array}$} & \multicolumn{3}{|c|}{ Autocorrelations } & \multicolumn{11}{|c|}{ Cross-correlations vith $\dot{y}_{t-i}$} \\
\hline & & & 1 & 2 & 3 & 12 & 8 & 4 & 2 & 1 & 0 & -1 & -2 & -4 & -8 & -12 \\
\hline A & & & \multicolumn{14}{|c|}{ Panel B: Yoments of Filtered Series (HP filter) } \\
\hline$\hat{\mathbf{y}}$ & 2.07 & 1.0 & .70 & .45 & .23 & -.23 & -.23 & .08 & .45 & .70 & 1.0 & .70 & .46 & .08 & -.23 & -.23 \\
\hline$\hat{c}$ & .63 & .26 & .86 & .69 & .62 & -.13 & .10 & .49 & .68 & .74 & .78 & .42 & .13 & -.23 & -.43 & -.29 \\
\hline$\hat{i}$ & 6.08 & 2.94 & .69 & .43 & .23 & -.24 & -.29 & .00 & .38 & .65 & .99 & .72 & .49 & -.16 & -.18 & -.21 \\
\hline$\hat{\boldsymbol{n}}$ & 1.36 & .65 & .69 & .43 & .22 & -.24 & -.31 & -.05 & .34 & .62 & .98 & .72 & .61 & .18 & -.15 & -.20 \\
\hline $\bar{\nabla}$ & .79 & .17 & .77 & .65 & .36 & -.19 & -.07 & .31 & .60 & .77 & .94 & .59 & .31 & -.08 & -.35 & -.28 \\
\hline$\hat{A}$ & 1.28 & .62 & .69 & .44 & .23 & -.24 & -.26 & .04 & .41 & .67 & 1.00 & .71 & .47 & .12 & -.20 & -.22 \\
\hline$\hat{\mathbf{k}}$ & .68 & .28 & .95 & .84 & .69 & .06 & .43 & .68 & .56 & .37 & .07 & -.15 & -.30 & -.46 & -.41 & -.19 \\
\hline$\dot{\mathbf{r}}$ & .07 & .03 & .69 & .43 & .22 & -.24 & -.36 & -.12 & .27 & .57 & .95 & .73 & .63 & .22 & -.10 & -.17 \\
\hline
\end{tabular}


Table III-3 (Continued)

EFFECTS OF FILTERING ON POPULATION MOMENTS

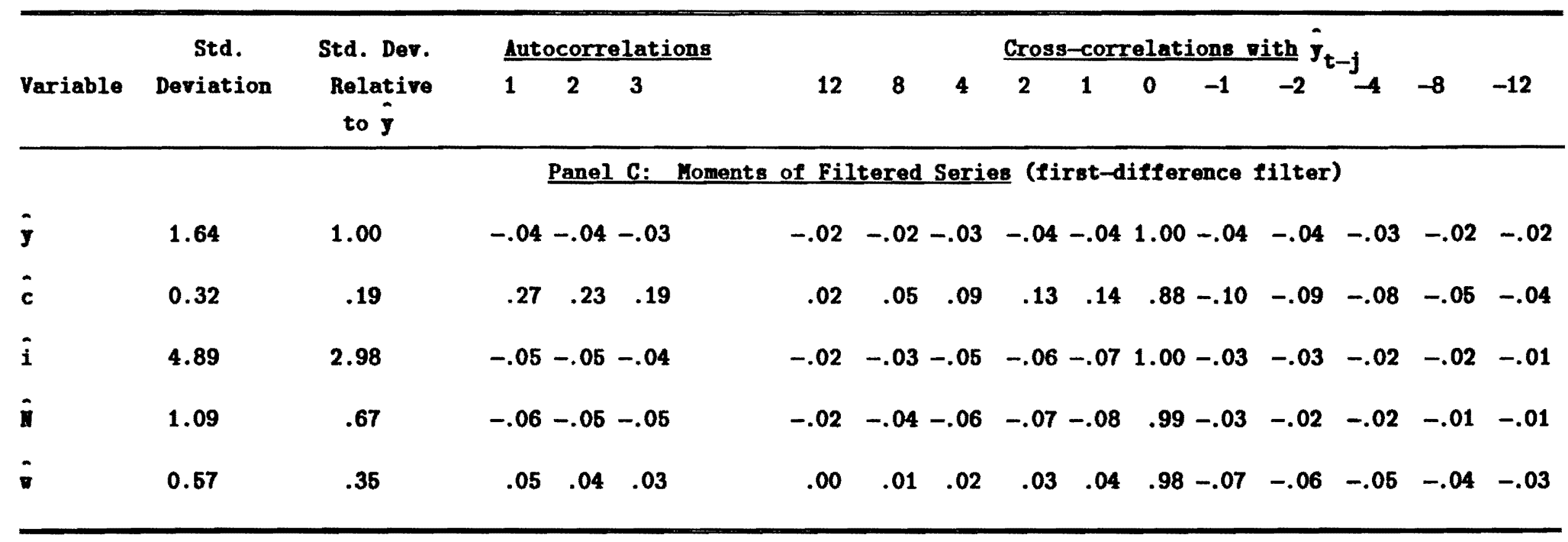

$\operatorname{man} 8901: t I I I 3$ 
Effects of Filtering on Population Moments: Unit Root Hodel

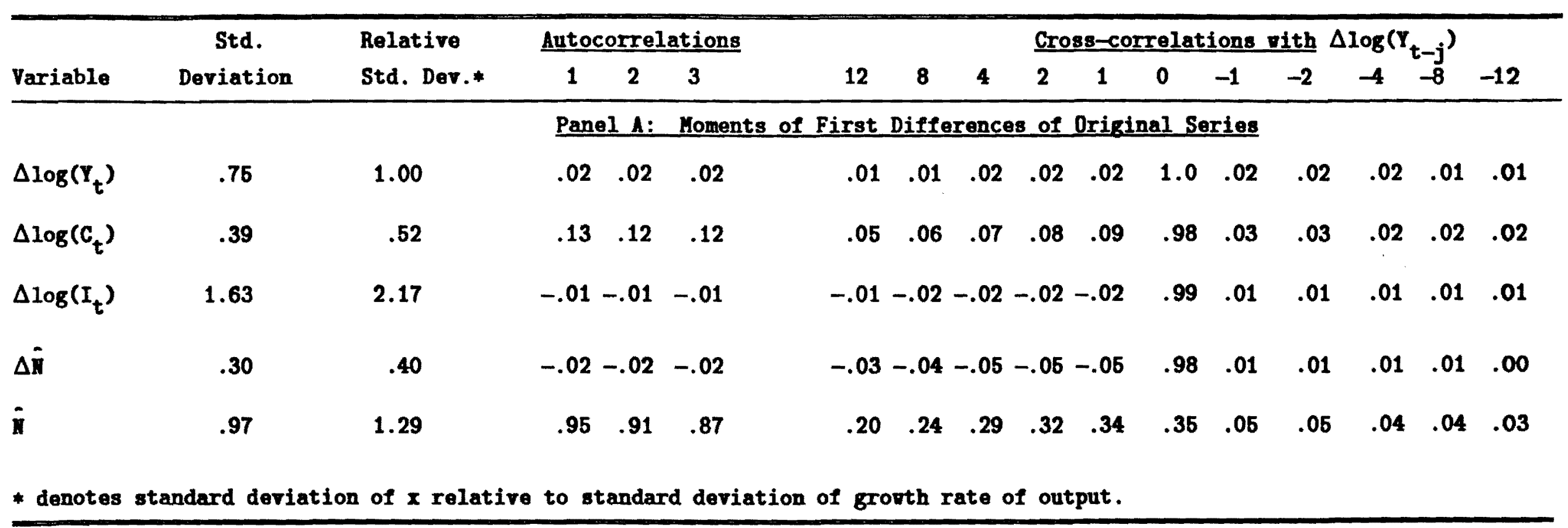


Table III-4 (Continued)

Effects of Filtering on Population Homents: Unit Root Fodel

\begin{tabular}{|c|c|c|c|c|c|c|c|c|c|c|c|c|c|c|c|c|}
\hline \multirow[b]{2}{*}{ Variable } & \multirow{2}{*}{$\begin{array}{c}\text { Std. } \\
\text { Deviation }\end{array}$} & \multirow{2}{*}{$\begin{array}{l}\text { Relative } \\
\text { Std. Dev.* }\end{array}$} & \multicolumn{3}{|c|}{ Autocorrelations } & \multirow[b]{2}{*}{12} & \multirow[b]{2}{*}{8} & \multicolumn{9}{|c|}{ Gross-correlations gith $\log \left(Y_{t-i}\right)$} \\
\hline & & & 1 & 2 & 3 & & & 4 & 2 & 1 & 0 & -1 & -2 & -4 & -8 & -12 \\
\hline & & \multicolumn{15}{|c|}{ Panel B: Moments of Filtered Series (HP Filter) } \\
\hline $\mathbf{Y}_{\mathbf{t}}$ & .99 & 1 & .68 & .47 & .28 & -.24 & -.20 & .13 & .47 & .68 & 1 & .68 & .47 & .13 & -.20 & \\
\hline $\mathbf{C}_{t}$ & .53 & .53 & .72 & .63 & .35 & -.21 & -.10 & .26 & .56 & .73 & .98 & .63 & .40 & .04 & -.29 & \\
\hline$I_{t}$ & 2.16 & 2.16 & .67 & .46 & .27 & -.26 & -.26 & .05 & .41 & .64 & .99 & .70 & .61 & .18 & -.16 & \\
\hline$\dot{\mathbf{H}}$ & .39 & .40 & .67 & .45 & .26 & -.27 & -.31 & -.02 & .35 & .60 & .98 & .71 & .53 & .23 & -.11 & \\
\hline
\end{tabular}

$\operatorname{man} 8901:$ tIII4 
Table IV-1

Monents of Alternative HP Grouth Components for Trend Stationary Neoclassical Model

\begin{tabular}{|c|c|c|c|c|c|c|c|c|c|c|c|c|c|c|c|c|}
\hline \multirow[b]{2}{*}{ Variable } & \multirow[b]{2}{*}{ sd } & \multirow[b]{2}{*}{$\operatorname{sd}(z) / \operatorname{sd}(y)$} & \multicolumn{4}{|c|}{ Autocorrelations } & \multicolumn{10}{|c|}{ Cross Correlations vith $\dot{y}_{t-j}$} \\
\hline & & & 1 & 2 & 3 & -12 & -8 & -4 & -2 & -1 & 0 & 1 & 2 & 4 & 8 & 12 \\
\hline \multicolumn{17}{|c|}{ Panel 1: Standard HP Grouth Conponent } \\
\hline$\hat{y}$ & 3.43 & 1.00 & 1.0 & .99 & .98 & .76 & .88 & .97 & .99 & 1.0 & 1.0 & 1.0 & .99 & .97 & .88 & .76 \\
\hline $\bar{c}$ & 2.60 & .76 & 1.0 & 1.00 & .99 & .95 & .98 & .96 & .93 & .92 & .90 & .88 & .85 & .80 & .68 & .56 \\
\hline$\hat{\mathbf{i}}$ & 6.63 & 1.93 & 1.0 & .99 & .97 & .44 & .63 & .80 & .86 & .89 & .91 & .93 & .94 & .95 & .91 & .81 \\
\hline$\hat{\mathbf{N}}$ & 1.27 & .37 & 1.0 & .98 & .96 & .08 & .31 & .52 & .61 & .65 & .69 & .72 & .75 & .78 & .79 & .73 \\
\hline$\ddot{v}$ & 2.71 & .79 & 1.0 & 1.0 & .99 & .92 & .97 & .98 & .97 & .95 & .94 & .92 & .90 & .86 & .75 & .62 \\
\hline$\dot{\mathbf{r}}$ & .08 & .02 & 1.0 & .99 & .97 & -.56 & -.36 & -.14 & -.03 & .02 & .06 & .11 & .15 & .22 & .31 & .33 \\
\hline$\vec{k}$ & 1.70 & .50 & 1.0 & .99 & .98 & .63 & .79 & .92 & .96 & .97 & .98 & .99 & .99 & .98 & .91 & .80 \\
\hline$i$ & 3.69 & 1.05 & 1.0 & 1.0 & .99 & .97 & .96 & .91 & .88 & .85 & .83 & .80 & .77 & .72 & .59 & .47 \\
\hline
\end{tabular}


Figure 1.1: Linear and HP Trends in Real GNP

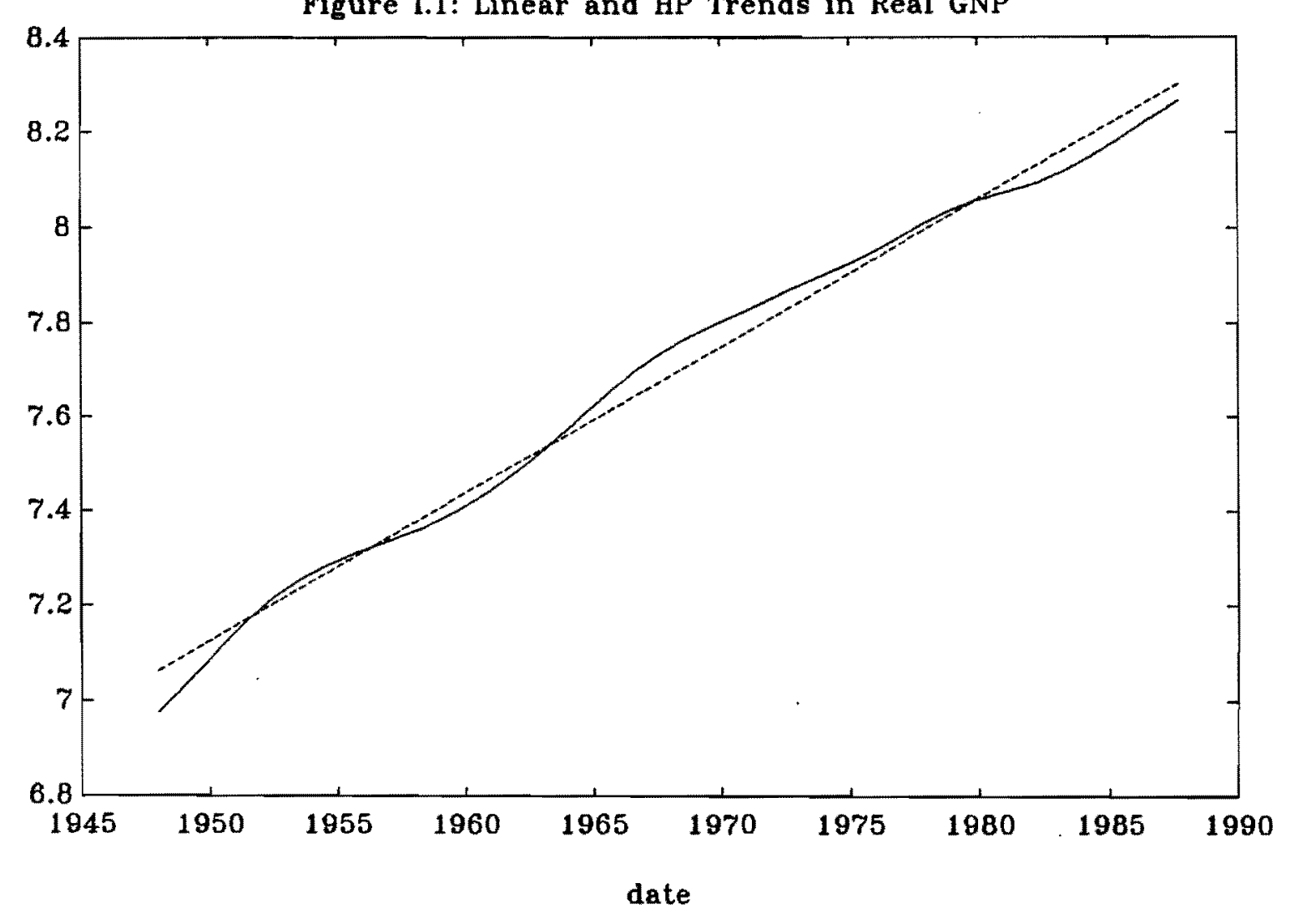

- - - - - LInear Trend Component of Logarithm of Real GNP HP Trend Component of Logarithm of Real GNP 


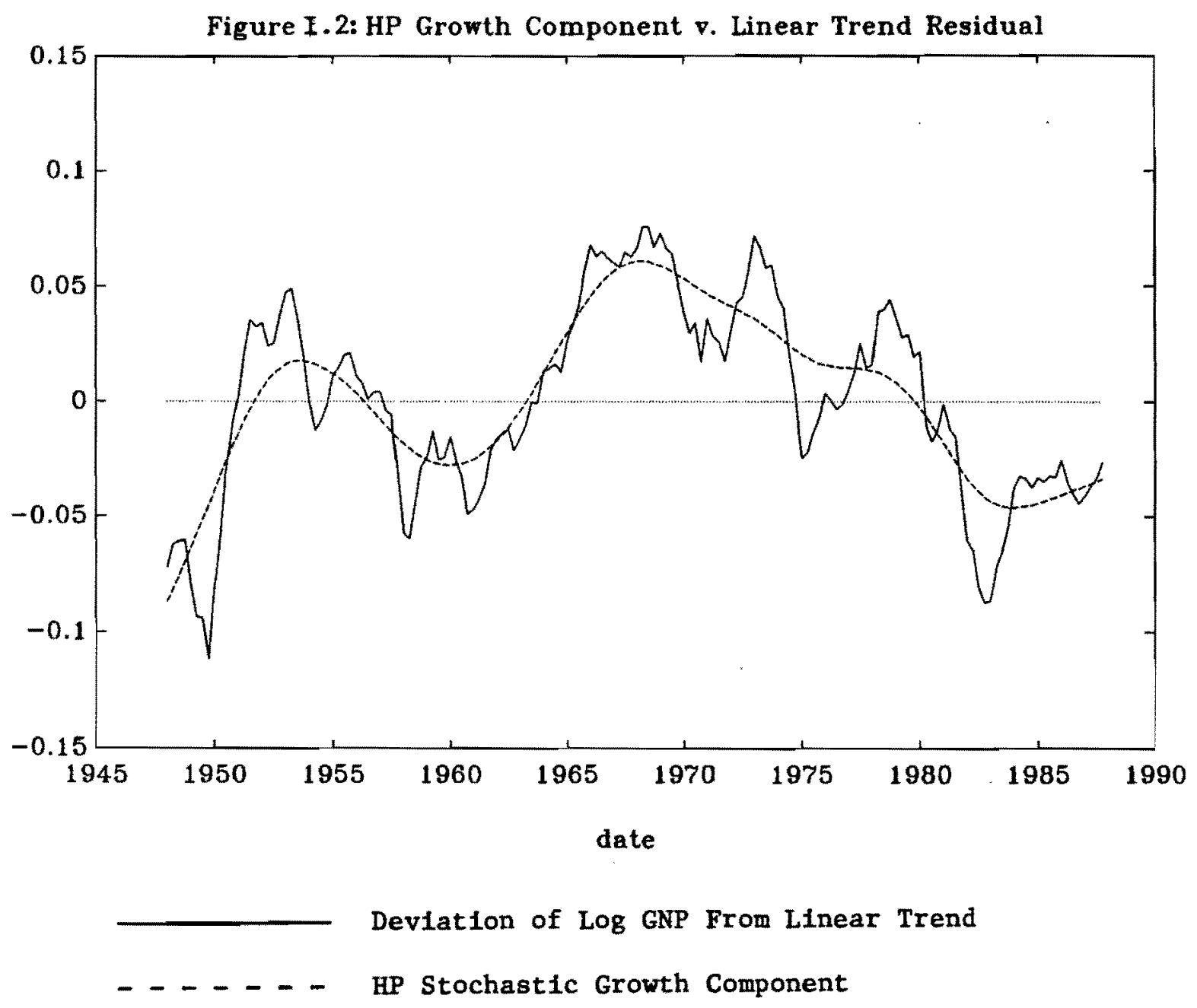




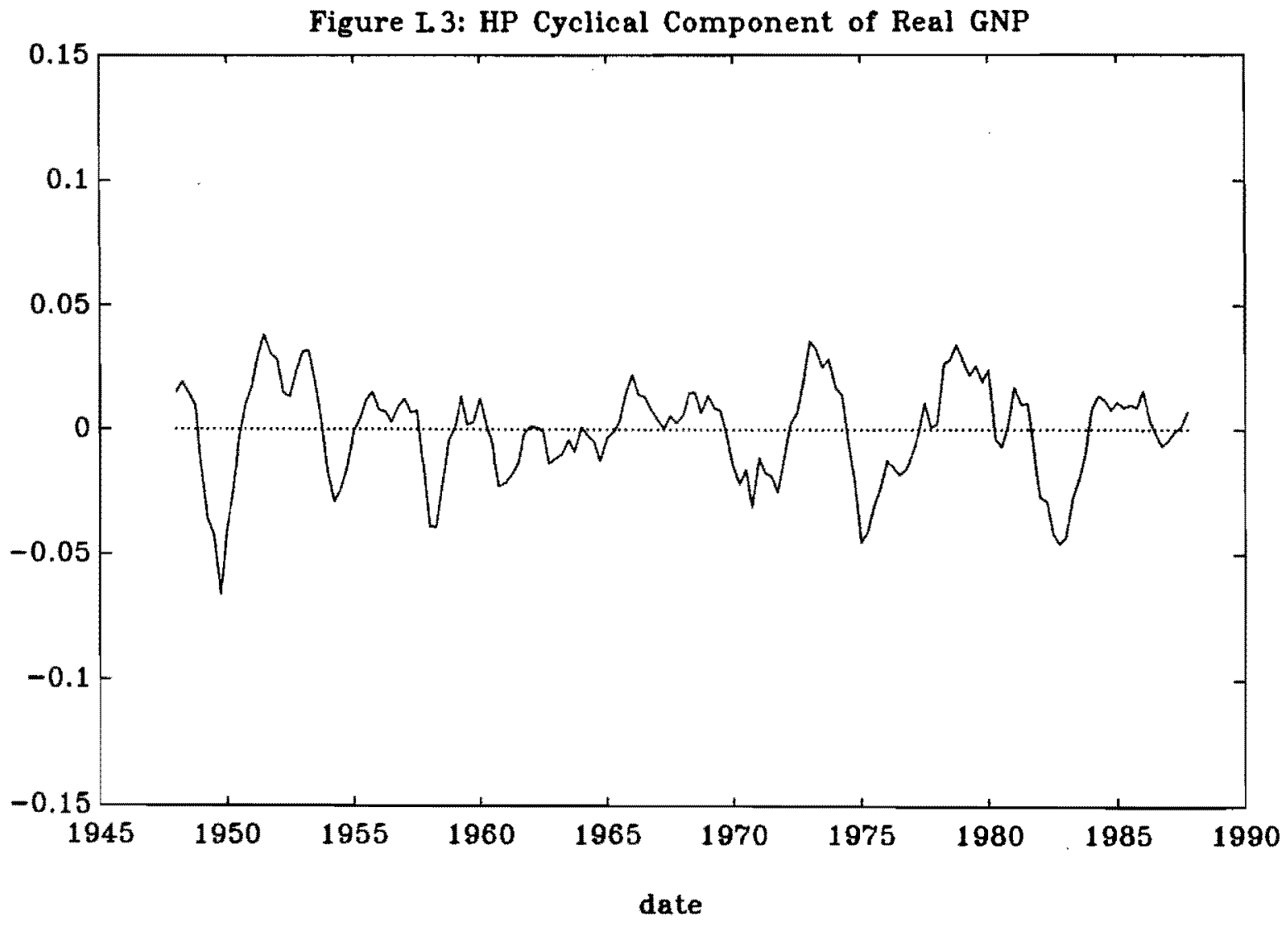




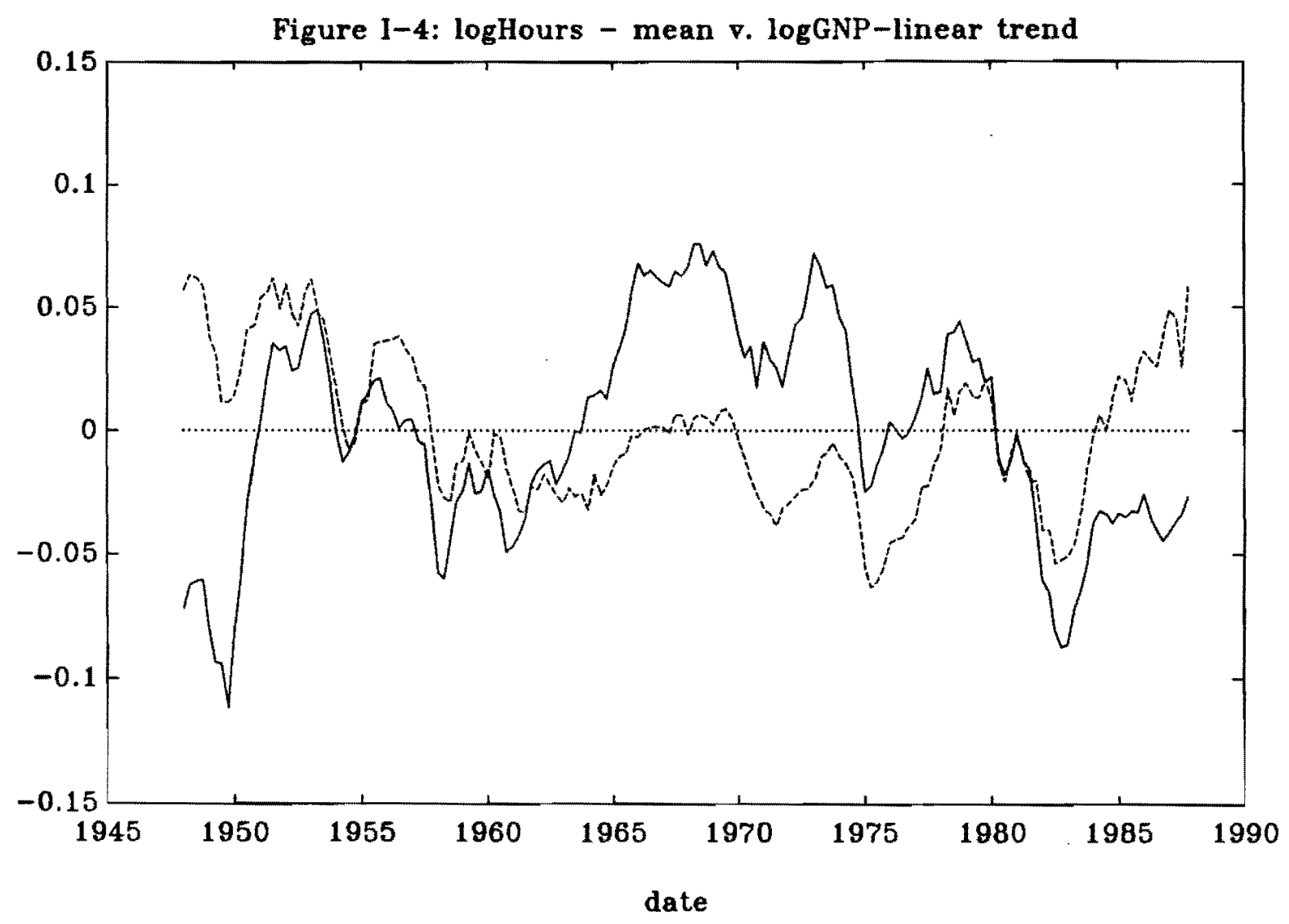
Deviation of Logarithm of Real GNP from Linear Trend
- - - - - Deviation of Logarithm of Per Capita Hours from Mean




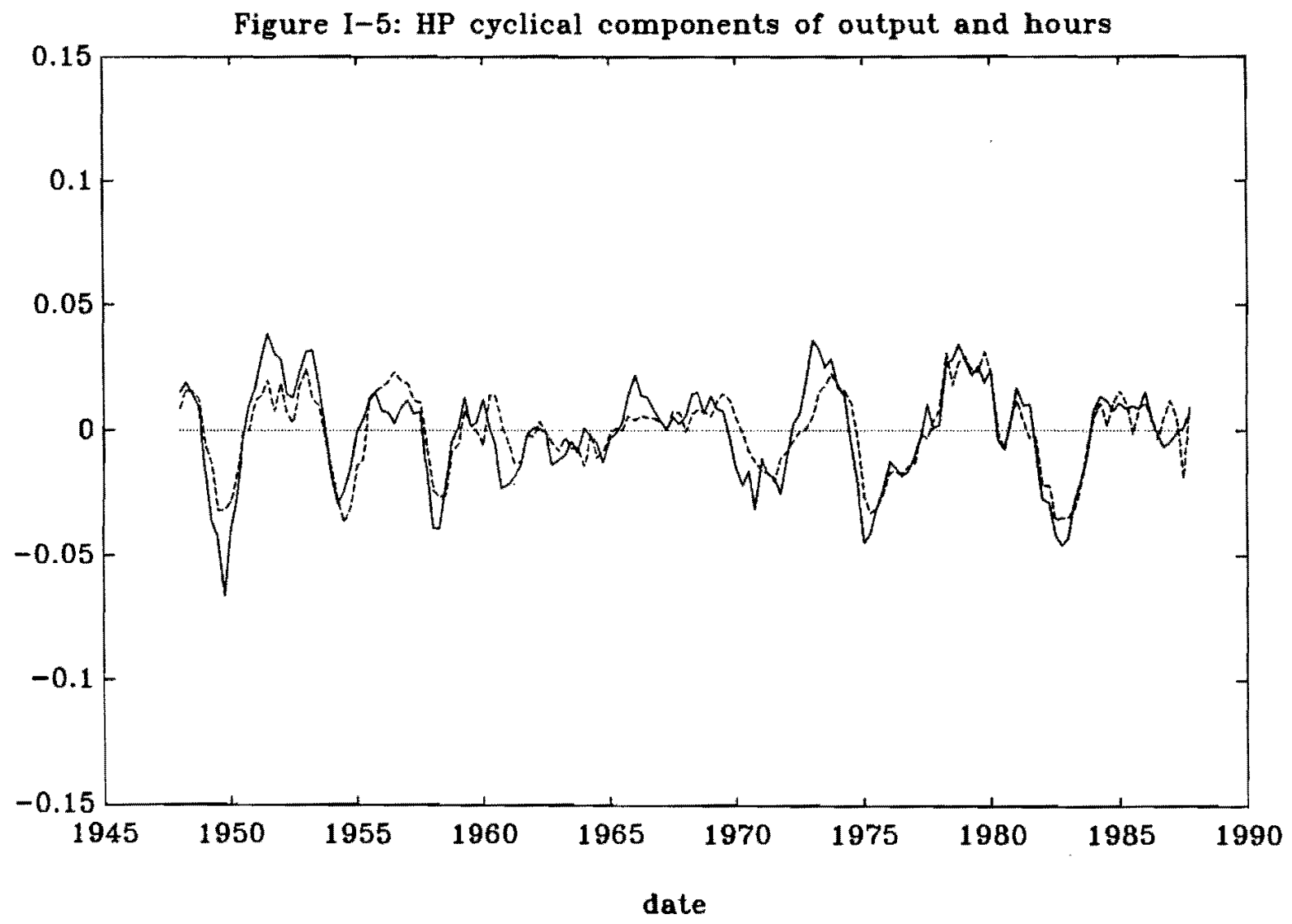

HP Cyclical Component of Logarithm of Rean GNP

- - - - - HP Cyclical Component of Logarithm of Per Capita Hours 

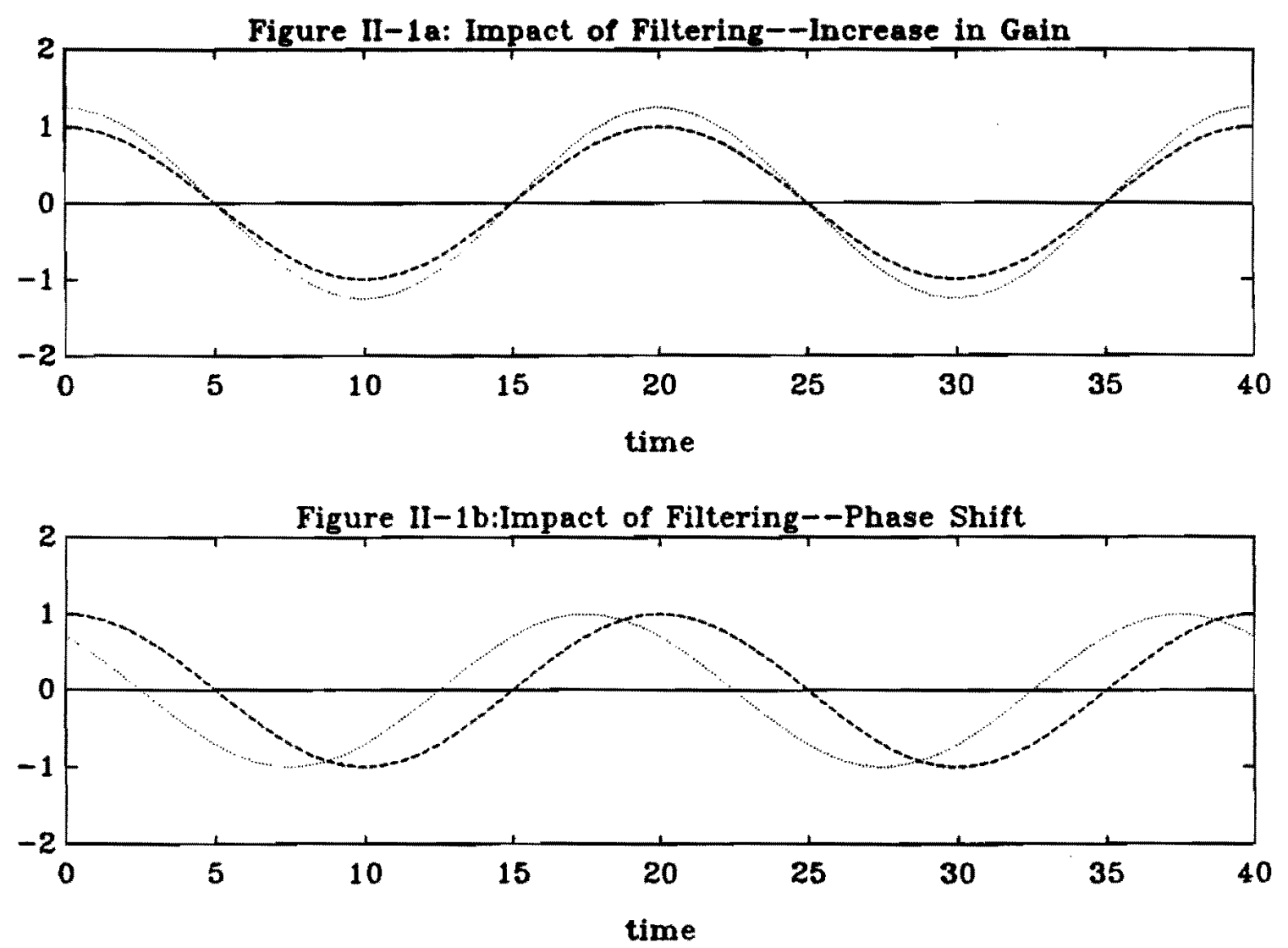

_. - . - Original Series

..... Filtered Series 

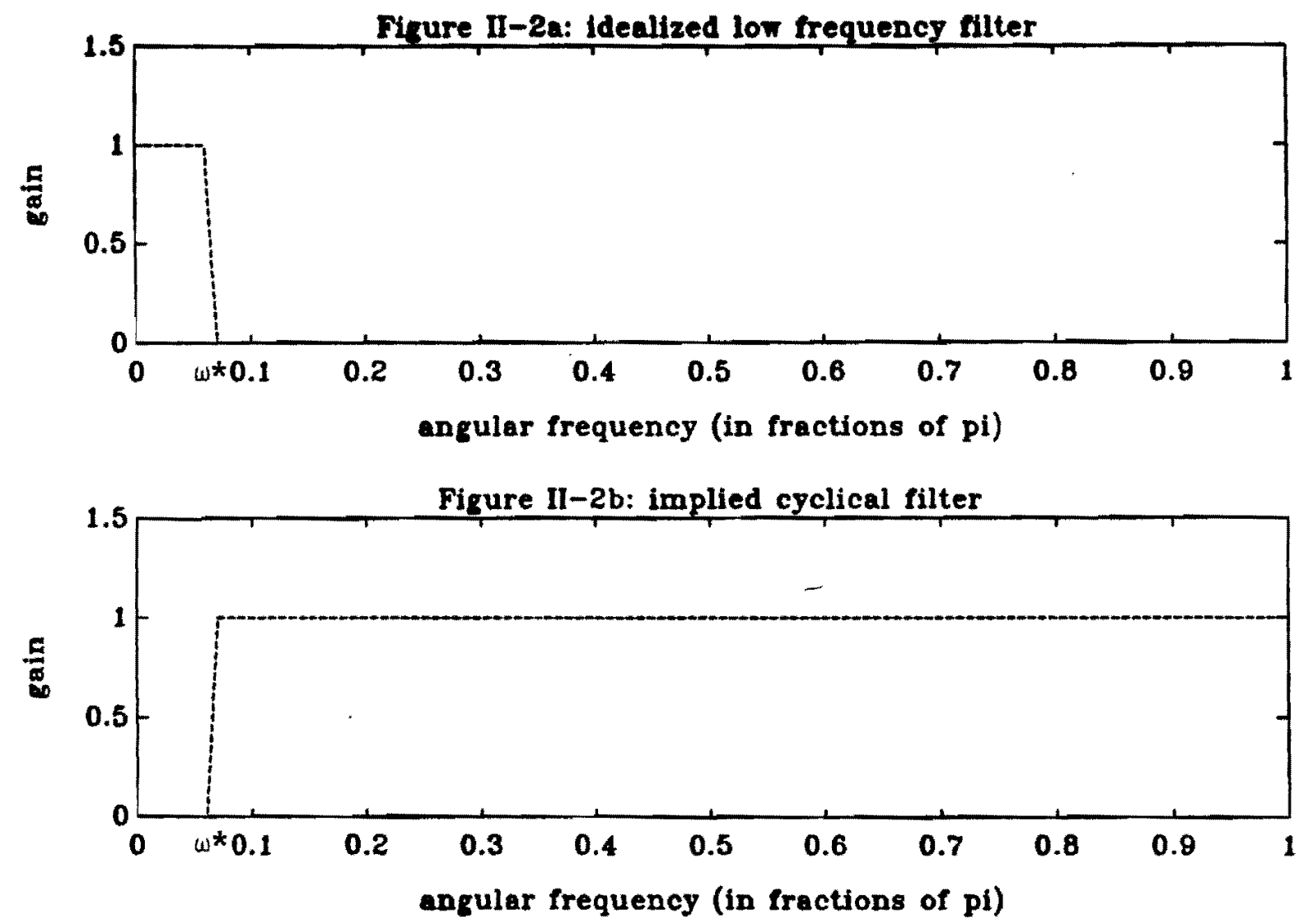


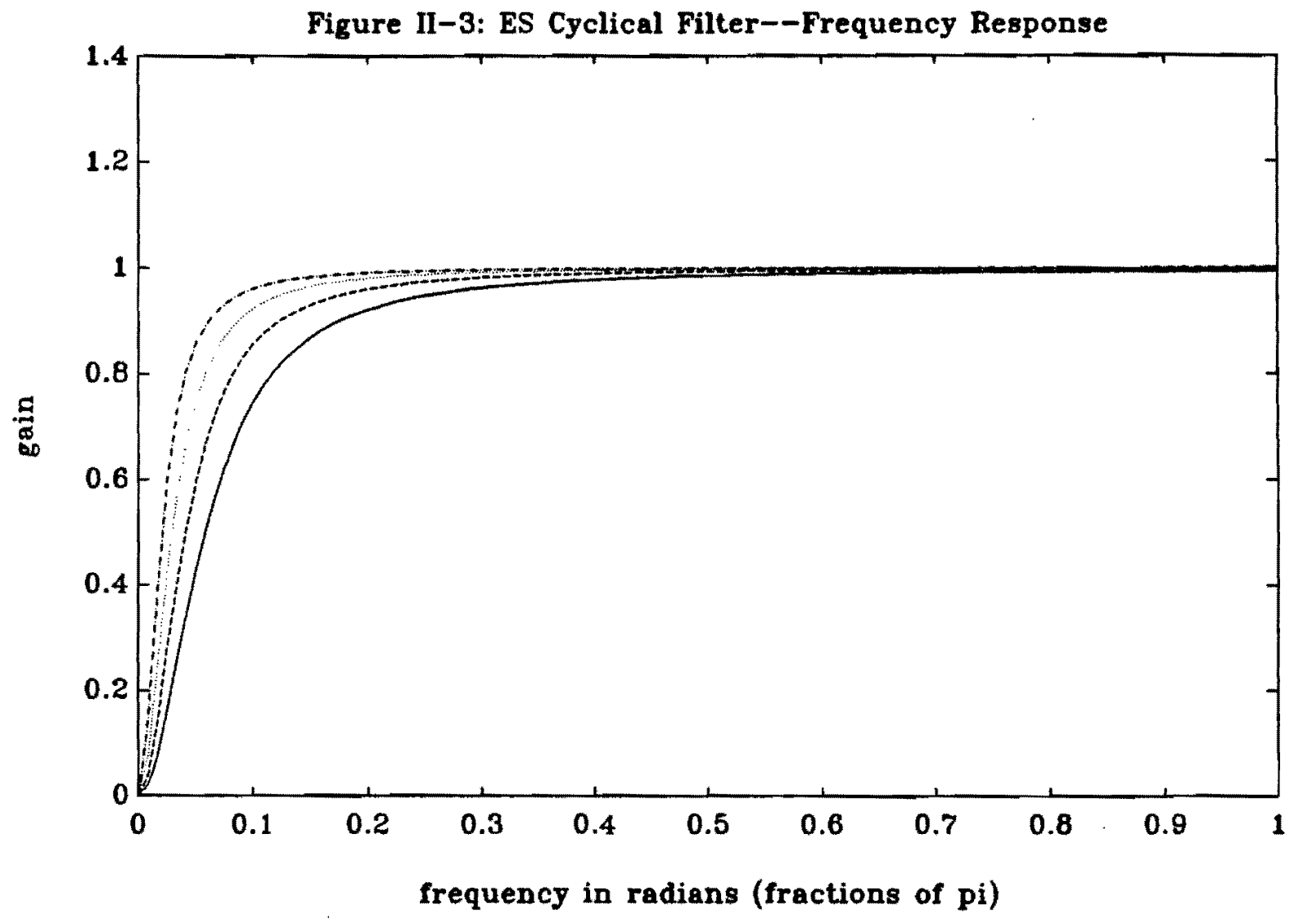

Smoothing Parameter Values $=\left[\begin{array}{llll}30 & 60 & 120 & 240\end{array}\right]$ 


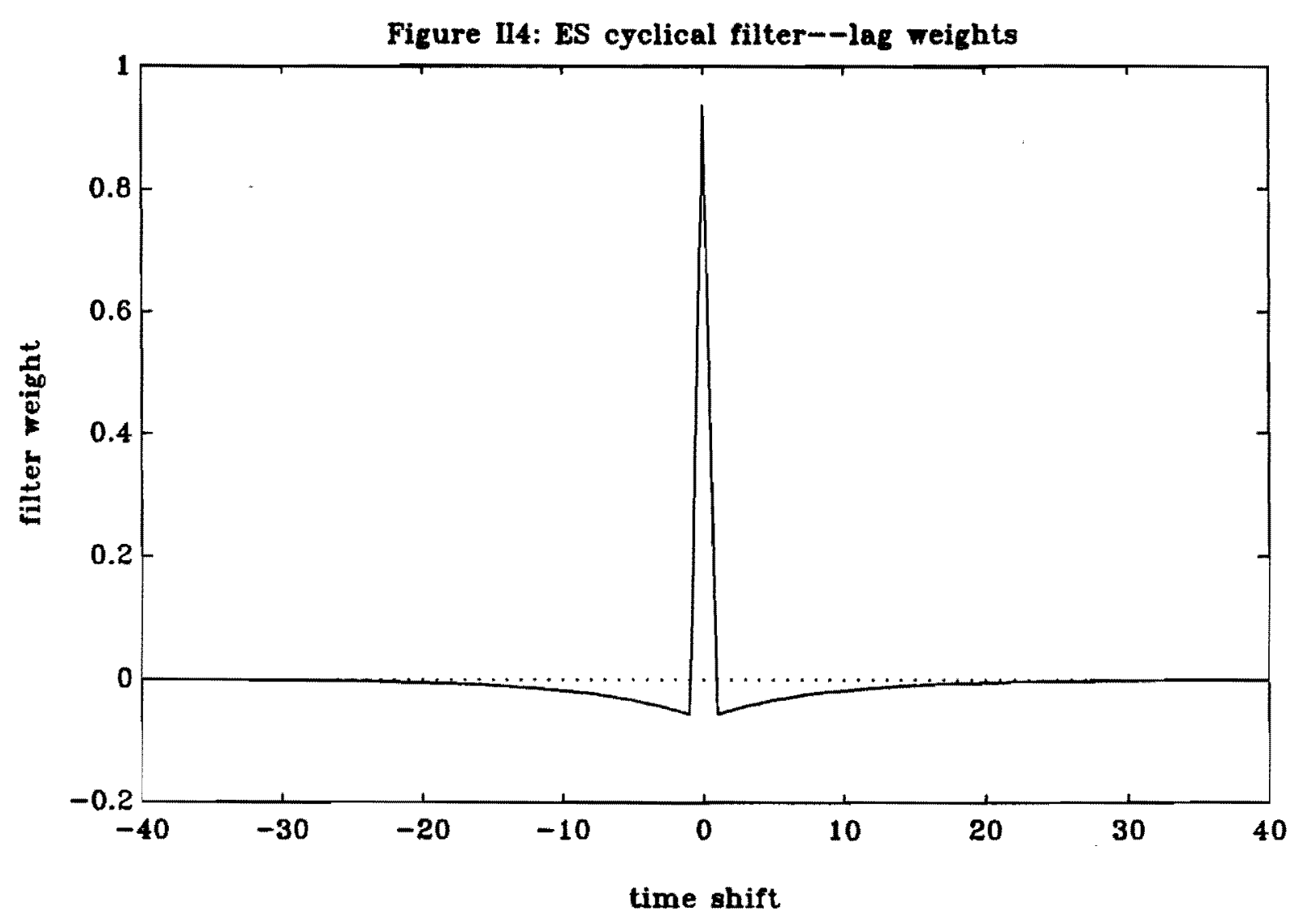

Smoothing Parameter Value $=60$ 


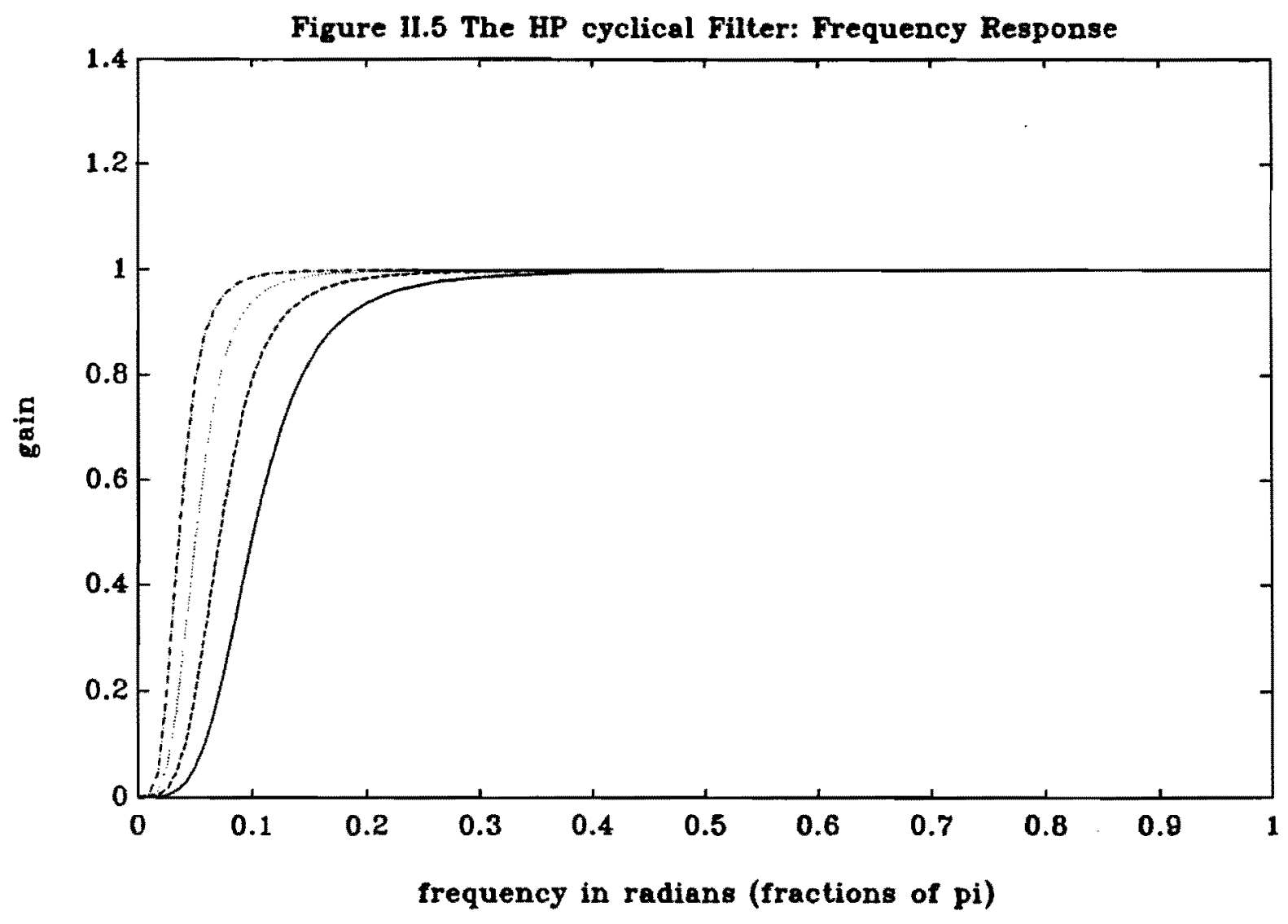

Smoothing Parameter Values $=\left[\begin{array}{llll}100 & 400 & 1600 & 6400\end{array}\right]$ 


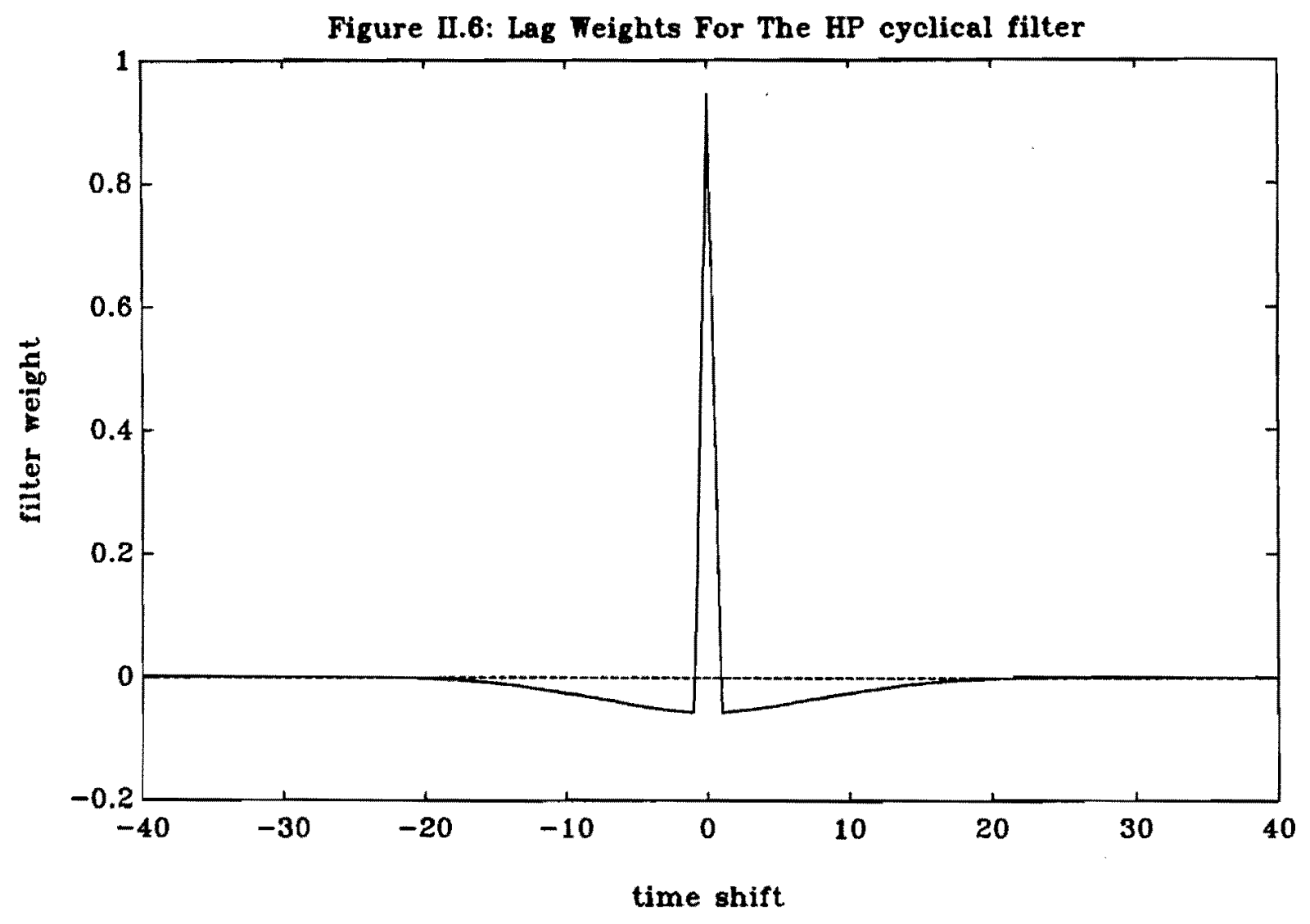

Smoothing Parameter Value $=1600$ 


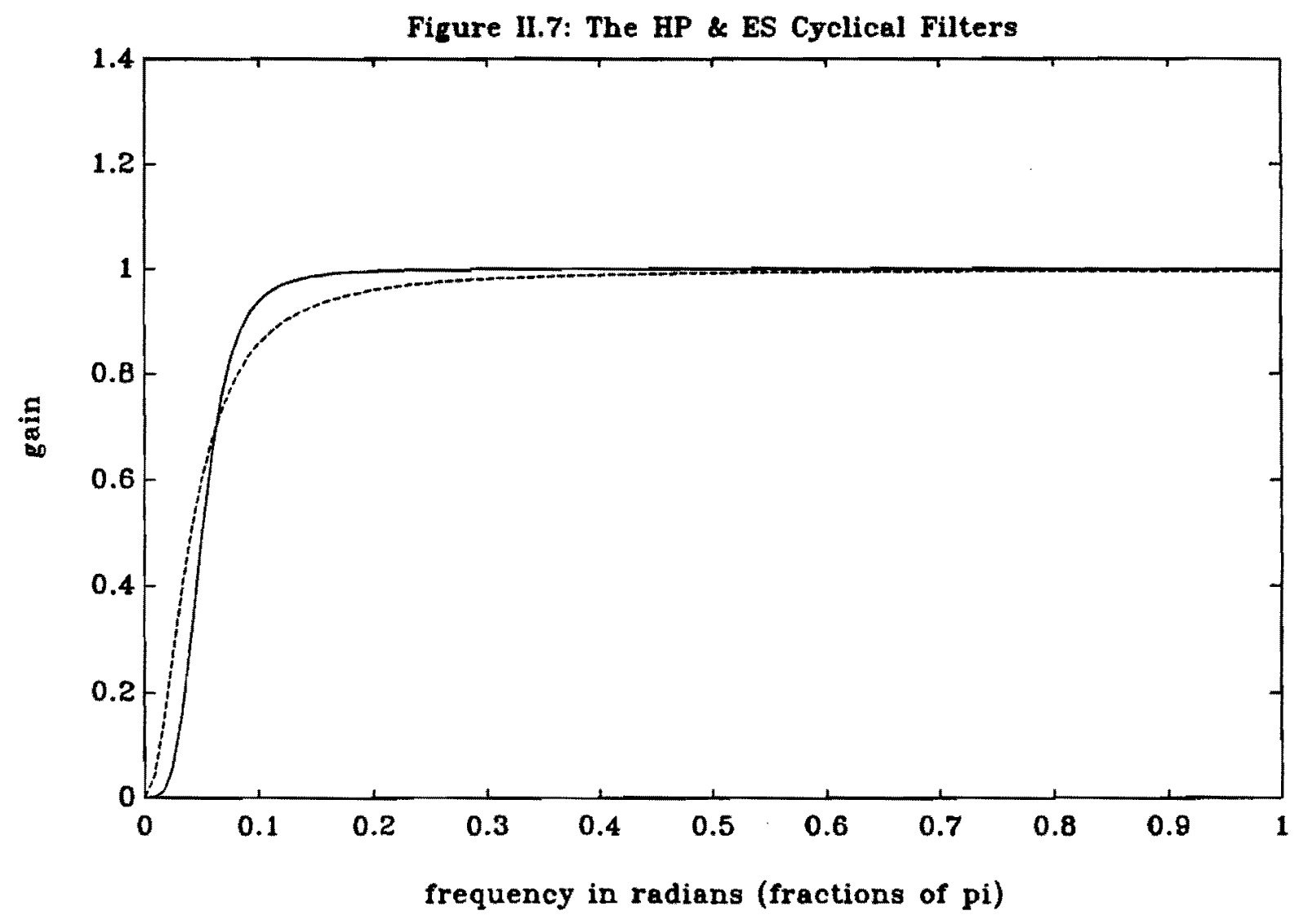

- - - - - ES Cyclical Filter

HP Cyclical Filter 
FIgure III.1: Implications of HP Filtering
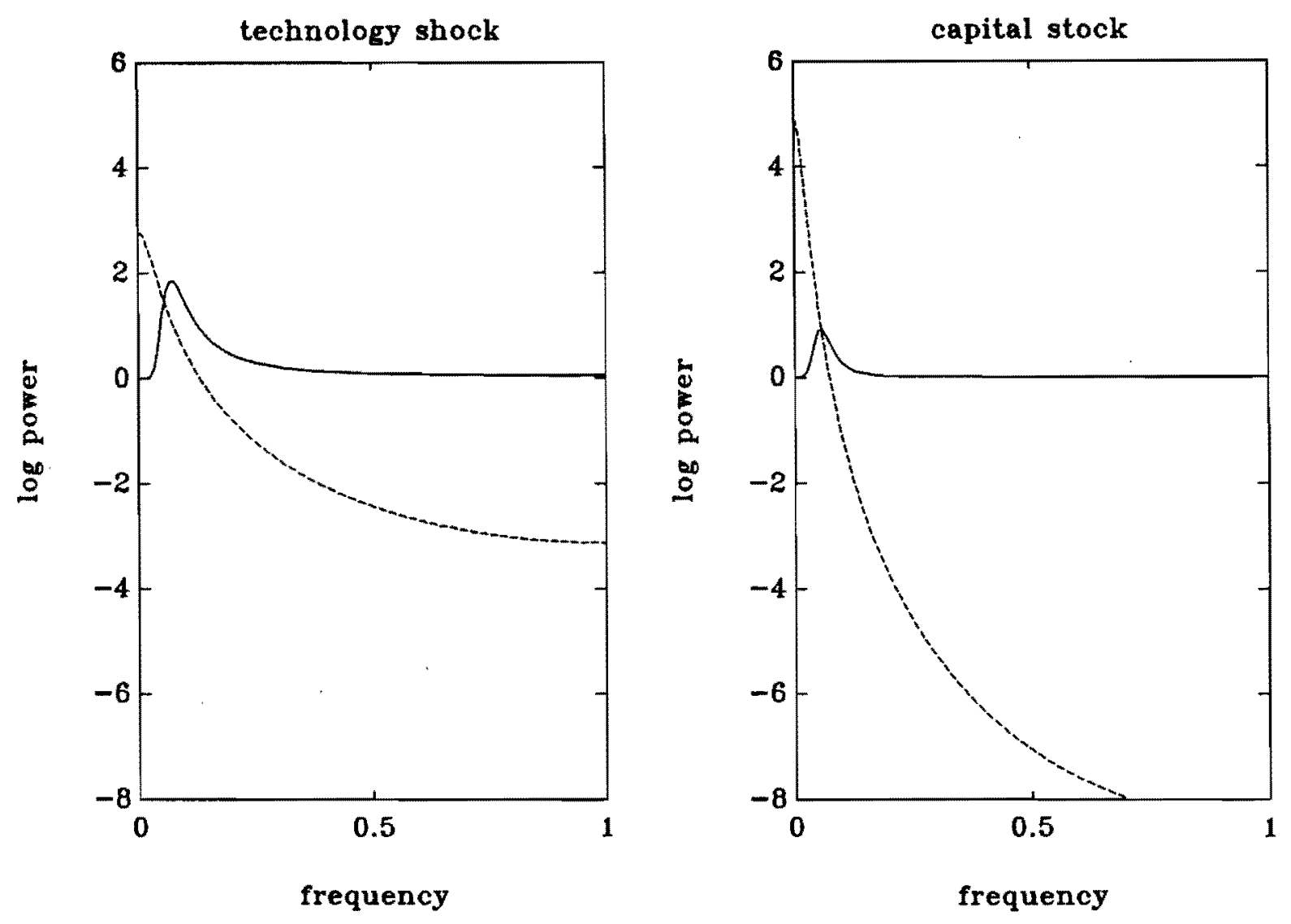

Unfiltered Spectral Density (GaIn Function) Filtered Spectral Density (Gain Function) 



\section{Rochester Center for Economic Research \\ University of Rochester \\ Department of Economics \\ Rochester, NY 14627 \\ 1988-1989 DISCUSSION PAPERS}

WP\#118 ADVERSE SELECTION, AGGREGATE UNCERTAINTY, AND THE ROLE FOR MUTUAL INSURANCE COMPANIES

by Bruce D. Smith and Michael J. Stutzer, February 1988

WP\#119 INTEREST ON RESERVES AND SUNSPOT EQUILIBRIA: FRIEDMAN'S PROPOSAL RECONSIDERED

by Bruce D. Smith, February 1988

WP\#120 INTERNATIONAL FINANCIAL INTERMEDIATION AND AGGREGATE FLUCTUATIONS UNDER ALTERNATIVE EXCHANGE RATE REGIMES

by Jeremy Greenwood and Stephen D. Williamson, February 1988

WP\#121 FINANCIAL DEREGULATION, MONETARY POLICY, AND CENTRAL BANKING by Marvin Goodfriend and Robert G. King, February 1988

WP\#122 BANK RUNS IN OPEN ECONOMIES AND THE INTERNATIONAL TRANSMISSION OF PANICS

by Peter M. Garber and Vittorio U. Grilli, March 1988

WP\#123 CAPITAL ACCUMULATION IN THE THEORY OF LONG RUN GROWTH by Paul M. Romer, March 1988

WP\#124 FINANCIAL INTERMEDIATION AND ENDOGENOUS GROWTH by Valerie R. Bencivenga and Bruce D. Smith, March 1988

WP\#125 UNEMPLOYMENT, THE VARIABILITY OF HOURS, AND THE PERSISTENCE OF "DISTURBANCES": A PRIVATE INFORMATION APPROACH by Bruce D. Smith, March 1988

WP\#126 WHAT CAN BE DONE WITH BAD SCHOOL PERFORMANCE DATA? by Eric Hanushek and Lori Taylor, March 1988

WP\#127 EQUILIBRIUM MARKETING STRATEGIES: IS THERE ADVERTISING; IN TRUTH? by Ignatius Horstmann and Glenn MacDonald, revised, March 1988

WP\#128 REAL EXCHANGE RATE VARIABILITY UNDER PEGGED AND FLOATING NOMINAL EXCHANGE RATE SYSTEMS: AN EQUILIBRIUM THEORY

by Alan C. Stockman, April 1988

WP\#129 POST-SAMPLE PREDICTION TESTS FOR GENERALIZED METHOD OF MOMENT ESTIMATORS

by Dennis Hoffman and Adrian Pagan, April 1988

WP\#130 GOVERNMENT SPENDING IN A SIMPLE MODEL OF ENDOGENOUS GROWTH by Robert J. Barro, May 1988 
WP\#131 FINANCIAL DEVELOPMENT, GROWTH, AND THE DISTRIBUTION OF INCOME by Jeremy Greenwood and Boyan Jovanovic, May 1988

WP\#132 EMPLOYMENT AND HOURS OVER THE BUSINESS CYCLE by Jang-Ok Cho and Thomas F. Cooley, May 1988

WP\#133 A REFINEMENT AND EXTENSION OF THE NO-ENVY CONCEPT by Dimitrios Diamantaras and William Thomson, May 1988

WP\#134 NASH SOLUTION AND UNCERTAIN DISAGREEMENT POINTS by Youngsub Chun and William Thomson, May 1988

WP\#135 NON-PARAMETRIC ESTIMATION AND THE RISK PREMIUM by Adrian Pagan and Y. Hong, May 1988

WP\#136 CHARACTERIZING THE NASH BARGAINING SOLUTION WITHOUT PARETO-OPTIMALITY

by Terje Lensberg and William Thomson, May 1988

WP\#137 SOME SIMULATION STUDIES OF NON-PARAMETRIC ESTIMATORS by $Y$. Hong and A. Pagan, June 1988

WP\#138 SELF-FULFILLING EXPECTATIONS, SPECULATIVE ATTACKS AND CAPITAL CONTROLS

by Harris Dellas and Alan C. Stockman, June 1988

WP\#139 APPROXIMATING SUBOPTIMAL DYNAMIC EQUILIBRIA: AN EULER EQUATION APPROACH by Marianne Baxter, June 1988

WP\#140 BUSINESS CYCLES AND THE EXCHANGE RATE SYSTEM: SOME INTERNATIONAL EVIDENCE

by Marianne Baxter and Alan C. Stockman, June 1988

WP\#141 RENT SHARING IN AN EQUILIBRIUM MODEL OF MATCHING AND TURNOVER by Kenneth J. McLaughlin, June 1988

WP\#142 CO-MOVEMENTS IN RELATIVE COMMODITY PRICES AND INTERNATIONAL CAPITAL FLOWS: A SIMPLE MODEL by Ronald W. Jones, July 1988

WP\#143 WAGE SENSITIVITY RANKINGS AND TEMPORAL CONVERGENCE by Ronald W. Jones and Peter Neary, July 1988

WP\#144 FOREIGN MONOPOLY AND OPTIMAL TARIFFS FOR THE SMALL OPEN ECONOMY by Ronald W. Jones and Shumpei Takemori, July 1988

WP\#145 THE ROLE OF SERVICES IN PRODUCTION AND INTERNATIONAL TRADE: A THEORETICAL FRAMEWORK by Ronald W. Jones and Henryk Kierzkowski, July 1988

WP\#146 APPRAISING THE OPTIONS FOR INTERNATIONAL TRADE IN SERVICES by Ronald W. Jones and Frances Ruane, July 1988 
WP\#147 SIMPLE METHODS OF ESTIMATION AND INFERENCE FOR SYSTEMS CHARACTERIZED BY DETERMINISTIC CHAOS

by Mahmoud El-Gamal, August 1988

WP\#148 THE RICARDIAN APPROACH TO BUDGET DEFICITS

by Robert J. Barro, August 1988

WP\#149 A MODEL OF NOMINAL CONTRACTS

by Bruce D. Smith, August 1988

WP\#150 A BUSINESS CYCLE MODEL WITH PRIVATE INFORMATION by Bruce D. Smith, August 1988

WP\#151 ASYMPTOTIC LIKELIHOOD BASED PREDICTION FUNCTIONS by Thomas F. Cooley, August 1988

WP\#152 MORAL HAZARD, IMPERFECT RISK-SHARING, AND THE BEHAVIOR OF ASSET RETURNS by James A. Kahn, August 1988

WP\#153 SPECIALIZATION, TRANSACTIONS TECHNOLOGIES, AND MONEY GROWTH by Harold Cole and Alan C. Stockman, August 1988

WP\#154 SAVINGS, INVESTMENT AND INTERNATIONAL CAPITAL FLOWS by Linda L. Tesar, August 1988

WP\#155 THE INFLATION TAX IN A REAL BUSINESS CYCLE MODEL by Thomas F. Cooley and Gary D. Hansen, August 1988

WP\#156 RAW MATERIALS, PROCESSING ACTIVITIES AND PROTECTIONISM by Ronald W. Jones and Barbara J. Spencer., September 1988

WP\#157 A TEST OF THE HARRIS ERGODICITY OF STATIONARY DYNAMICAL ECONOMIC MODELS

by Ian Domowitz and Mahmoud El-Gamal, September 1988

WP\#158 SYMMETRIC STOCHASTIC GAMES OF RESOURCE EXTRACTION: THE EXISTENCE OF NON-RANDOMIZED STATIONARY EQUILIBRIUM

by Mukul Majumdar and Rangarajan Sundaram, September 1988

WP\#159 SOME CONSEQUENCES OF CREDIT RATIONING IN AN ENDOGENOUS GROWTH MODEL by Valerie Bencivenga and Bruce Smith, September 1988

WP\#160 COMPETITIVE DIFFUSION

by Boyan Jovanovic and Glenn MacDonald, September 1988

WP\#161 EXCHANGE RATES, THE CURRENT ACCOUNT, AND MONETARY POLICY by Alan C. Stockman, October 1988

WP\#162 DIAGNOSTIC TESTS FOR MODELS BASED ON INDIVIDUAL DATA: A SURVEY by Adrian Pagan and Frank Vella, October 1988 
WP\#163 EFFICIENCY BOUND CALCULATIONS FOR A TIME SERIES MODEL WITH CONDITIONAL HETEROSKEDASTICITY

by John Heaton and Masao Ogaki, November 1988

WP\#164 TAX ANALYSIS IN A DYNAMIC STOCHASTIC MODEL ON MEASURING HARBERGER TRIANGLES AND OKUN GAPS by Jeremy Greenwood and Gregory W. Huffman, November 1988

WP\#165 THE POSITIVE ECONOMICS OF METHODOLOGY

by James A. Kahn, Steven E. Landsburg, and Alan C. Stockman, November 1988

WP\#166 MULTIPLIERS IN EQUILIBRIUM BUSINESS CYCLE MODELS

by Marianne Baxter and Robert G. King, November 1988

WP\#167 DYNAMIC REAL TRADE MODELS: NEW DIRECTIONS FOR OPEN ECONOMY MACROECONOMICS

by Marianne Baxter, December 1988

WP\#168 WHY IS PRODUCTION MORE VOLATILE THAN SALES? THEORY AND EVIDENCE ON THE STOCKOUT-AVOIDANCE MOTIVE FOR INVENTORY-HOLDING

by James A. Kahn, December 1988

WP\#169 BUSINESS CYCLES, STYLIZED FACTS, AND THE EXCHANGE RATE REGIME:

EVIDENCE FROM THE UNITED STATES

by Marianne Baxter, December 1988

WP\#170 THE INDIRECT AND DIRECT SUBSTITUTION EFFECTS

by Masao Ogaki, December 1988

WP\#171 RATIONAL RESPONSE TO UNPRECEDENTED POLICIES: THE 1979 CHANGE IN FEDERAL RESERVE OPERATING PROCEDURES

by Marianne Baxter, January 1989

WP\#172 THE TRAGEDY OF THE COMMONS? A CHARACTERIZATION OF STATIONARY PERFECT EQUILIBRIUM IN DYNAMIC GAMES

by Prajit K. Dutta and Rangarajan K. Sundaram, January 1989

WP\#173 EXTERNALITIES AND ASYMMETRIC INFORMATION

by Jeremy Greenwood and R. Preston McAfee, January 1989

WP\#174 TESTING FOR CONTRACTING EFFECTS ON EMPLOYMENT

by Mark Bils, January 1989

WP\#175 CREDIBLE BORROWING CONSTRAINTS WITH RENEGOTIABLE DEBT

by James A. Kahn, February 1989

WP\#176 REAL EXPECTATIONS: A HARMONY THEORETIC APPROACH TO DECISION MAKING UNDER UNCERTAINTY

by Mahmoud A. El-Gamal, February 1989

WP\#177 COOPERATIVE MODELS OF BARGAINING

by William Thomson, February 1989 
WP\#178 NO-ENVY, CONSISTENCY AND MONOTONICITY IN ECONOMIES WITH INDIVISIBILITIES

by Koichi Tadenuma and William Thomson, March 1989

WP\#179 OUTPUT GROWTH, THE REAL WAGE, AND EMPLOYMENT FLUCTUATIONS

by Zvi Hercowitz and Michael Sampson, March 1989

WP\#180 MIGRATION BETWEEN HOME COUNTRY AND DIASPORA: AN ECONOMIC ANALYSIS by Zvi Hercovitz and David Pines, March 1989

WP\#181 NONPARAMETRIC HAZARD ESTIMATION WITH TIME VARYING DISCRETE COVARIATES

by Siu Fai Leung and Wing Hung Wong, March 1989

WP\#182 NEW PREDICTIONS FROM THE ECONOMICS OF UNIONISM by Glenn M. MacDonald and Christopher Robinson, March 1989

WP\#183 REPEATED GAMES, FINITE AUTOMATA, AND COMPLEXITY by Jeffrey S. Banks and Rangarajan K. Sundaram, April 1989

WP\#184 INTERTEMPORAL SUBSTITUTION AND $\lambda$-CONSTANT COMPARATIVE STATICS by Kenneth J. McLaughlin, April 1989

WP\#185 THE STOCK MARKET AND INVESTMENT

by Robert J. Barro, May 1989

WP\#186 GOVERNMENT SPENDING IN A SIMPLE MODEL OF ENDOGENOUS GROWTH by Robert J. Barro, May 1989

WP\#187 NEW CLASSICALS AND KEYNESIANS, OR THE GOOD GUYS AND THE BAD GUYS by Robert J. Barro, May 1989

WP\#188 THE CYCLICAL BEHAVIOR OF PRICES

by Thomas F. Cooley and Lee E. Ohanian, May 1989

WP\#189 BARGAINING PROBLEMS WITH CLAIMS

by Youngsub Chun and William Thomson, June 1989

WP\#190 ENTRY AND EXIT IN PERFECT COMPETITION: PART I: THEORY

by Boyan Jovanovic and Glenn M. MacDonald, June 1989

WP\#191 MARKET EQUILIBRIA WITH NOT-FOR-PROFIT FIRMS

by Charles E. Phelps and Itai Sened, June 1989

WP\#192 THE CONSISTENCY PRINCIPLE

by William Thomson, August 1989

WP\#193 TRANSVERSALITY CONDITION AND OPTIMALITY IN A CLASS OF INFINITE HORIZON CONTINUOUS TIME ECONOMIC MODELS

by Siu Fai Leung, August 1989

WP\#194 VERTICAL FORECLOSURE AND INTERNATIONAL TRADE POLICY

by Barbara J. Spencer and Ronald W. Jones, August 1989 
WP\#195 TRADE AND PROTECTION IN VERTICALLY RELATED MARKETS

by Barbara J. Spencer and Ronald W. Jones, August 1989

WP\#196 COMMUNICATION AND EFFICIENCY IN COORDINATION GAMES

by Jeffrey S. Banks and Randall L. Calvert, August 1989

WP\#197 FULL INSURANCE IN THE PRESENCE OF AGGREGATE UNCERTAINTY

by Barbara J. Mace, August 1989

WP\#198 UNDERSTANDING REAL BUSINESS CYCLES

by Charles I. Plosser, August 1989

WP\#199 A SIMPLE ESTIMATOR FOR SIMULTANEOUS MODELS WITH CENSORED ENDOGENOUS REGRESSORS

by Frank Vella, August 1989

WP\#200 DYNAMIC INEFFICIENCY IN AN ECONOMY WITH LAND

by Changyong Rhee, August 1989

WP\#201 ECONOMIC GROWTH IN A CROSS SECTION OF COUNTRIES

by Robert J. Barro, September 1989

WP\#202 ADVERSE SELECTION IN THE OVERLAPPING GENERATIONS MODEL

by Costas Azariadis and Bruce D. Smith, October 1989

WP\#203 MULTIPLE AND SUNSPOT EQUILIBRIA UNDER INTEREST RATE AND MONEY SUPPLY RULES

by Bruce D. Smith, October 1989

WP $\$ 204$ REAL BUSINESS CYCLES AND THE TEST OF THE ADELMANS

by Robert G. King and Charles I. Plosser, October 1989

WP $\$ 205$. LOW FREQUENCY FILTERING AND REAL BUSINESS CYCLES

by Robert G. King and Sergio T. Rebelo, October 1989

WP\#206 TRANSITIONAL DYNAMICS AND ECONOMIC GROWTH IN THE NEOCLASSICAL MODEL by Robert G. King and Sergio T. Rebelo, November 1989 
